\title{
Isovitexin, a main Flavonoid Compound from Celtis Sinensis Pers. Leaves, Exerts Activity Against Inflammation caused by Contacting Ginkgolic Acids in Ginkgo Fruit through Downregulating SHP2 Activation
}

\author{
yiwei zhang \\ Nanjing Forestry University \\ zhipeng qi \\ Nanjing Forestry University \\ wenjie wang \\ Nanjing Forestry University \\ lei wang \\ Nanjing Forestry University \\ Fuliang cao \\ Nanjing Forestry University \\ linguo zhao \\ Nanjing Forestry University \\ xianying fang ( $\square$ fxy_08@163.com ) \\ Nanjing Forestry University
}

\section{Research Article}

Keywords: isovitexin, ginkgolic acids, dermatitis, inflammation, SHP2, Celtis sinensis Pers, leaves

Posted Date: March 19th, 2021

DOl: https://doi.org/10.21203/rs.3.rs-287595/v1

License: (c) (1) This work is licensed under a Creative Commons Attribution 4.0 International License.

Read Full License 


\section{Abstract}

It has been reported that Celtis sinensis Pers. is employed as a folk medicine for the treatment of inflammation diseases. But the mechanism supporting its use as anti-inflammatory remain unclear. To investigate the anti-inflammatory of Celtis sinensis Pers. ICR mice were provided Celtis sinensis Pers. leaf extract (CLE) at $100,200 \mathrm{mg} / \mathrm{kg}$ after ginkgolic acids (GA) sensitization. Our data showed that CLE and the main flavonoid isovitexin in CLE could ameliorate GA-induced contact dermatitis in mice. Ear swelling, inflammatory cell infiltration and splenomegaly were inhibited significantly by isovitexin, while the weight loss of mice in the isovitexin-treated group was much better than that in the dexamethasone-treated group (positive control drug). It has been reported in previous research that GA-induced inflammation is closely related to the $T$ cell response. Therefore, $T$ cells were the focus of the anti-inflammatory effect of isovitexin in this paper. The in vivo results showed that isovitexin $(10,20 \mathrm{mg} / \mathrm{kg})$ inhibited the expression of proinflammatory cytokines (TNF-a, IFN-y, IL-2 and IL-17A) in lymph nodes, inhibited the secretion of cytokines into the serum from mice with contact dermatitis and promoted the expression of apoptosisrelated proteins. In vitro, isovitexin also induced apoptosis and proinflammatory cytokine expression in Con A-activated T cells. Further study showed that the MAPK and STAT signaling pathways and the phosphorylation of SHP2 were inhibited by isovitexin. Both molecular docking and biological experiments indicated that SHP2 may be an anti-inflammatory target of isovitexin in T cells. Taken together, isovitexin can serve as a potential natural agent for the treatment or prevention of GA-induced inflammatory problems.

\section{Introduction}

Ginkgo fruit, the seeds of Ginkgo biloba L., has been used as a nutritious food for thousands of years, and a variety of medicinal effects have been attributed to the ginkgo fruit. The main active pharmaceutical ingredients in Ginkgo biloba include oxyglycoside flavonoids, terpene trilactones, proanthocyanidins and so on ${ }^{1,2}$. However, food poisoning by ginkgo fruit has been reported in Japan and China, which presents as frequent vomiting and generalized convulsions ${ }^{3}$. Ginkgolic acids (GA), the alkylphenol constituents in ginkgo fruit (ginkgo seeds), have been considered one of the potential toxic components in Ginkgo biloba. The functional disorders are probably due to $\mathrm{GA}^{4}$. It has also been reported that contact allergic dermatitis (ACD) can be induced by ginkgolic acids when people contact ginkgo leaves during the picking of ginkgo fruit ${ }^{5,6}$. Ginkgo biloba leaves exhibit useful applications in health, food and dietary supplements but are also controversial in the application of some aspects because of the existence of GA. Under some conditions, GA can be separated by organic solvent extraction or column chromatography ${ }^{7}$. However, for raw material products such as ginkgo fruits and ginkgo tea, the GA removal process cannot be performed ${ }^{8,9}$. Other methods, such as detoxification by compatibility, need to be taken to solve the GA-caused toxicity problems in the application of ginkgo fruits and ginkgo tea.

Although a high dose of GA causes some diseases, it also shows pharmacological effects, such as antibacterial and antitumor effects ${ }^{10,11}$. Therefore, a strategy to reduce the side effects of GA should be 
different from other inactive compounds. The strategy could be a therapeutic that ameliorates GAinduced diseases in the form of a compound added to ginkgo products where GA cannot be separated effectively, such as ginkgo fruits and ginkgo tea.

GA, a derivative of alkyl-substituted salicylic acid, is similar to the chemical structure of urushiol and differs by carbon number and unsaturation, classified as $C 13: 0, C 15: 1, C 15: 0$, and $C 17: 1^{12}$. Allergies caused by paint occur frequently in our daily lives. As an allergen from paint, urushiol can cause intense, persistent itch, skin rashes and a burning sensation in severe cases ${ }^{13}$. The clinical manifestations of GAinduced ACD are similar to urushiol-induced ACD, followed by the appearance of erythematous edematous plaques and papulovesicles accompanied by intense pruritus on the forearms in severe cases $^{14}$. These inflammatory reactions can lead to a series of problems, such as skin injury, immune liver injury, gastrointestinal inflammatory injury and so on. With an important role in the immune response, $T$ cells appear to proliferate and differentiate. However, overdeveloped T cells are associated with cutaneous allergic and inflammatory responses, which exacerbate skin inflammation, tissue injury and other immunopathies. In a previous study, reports suggested that the mechanism of GA-induced ACD may be consistent with urushiol-induced ACD. Numerous experimental animal models have validated GA as a hapten with the ability to activate $T$ cells against innocuous or autoantigens and induce type IV allergic reactions ${ }^{15}$. A study has shown that $T$ cells in rats sensitized with GA are differentiated into CD $4^{+}$ T cells, suggesting that GA may act as an allergen to enhance body sensitivity, induce $T$ cell division and proliferation and enhance the cellular immune response.

Celtis sinensis Pers. has been used as a traditional herbal remedy for thousands of years in China. It was used to treat urushiol-induced dermatitis. There is a folk tale, from the Maolan karst forest, that if someone contacted poison ivy inadvertently, he could be treated by putting the leaves of Celtis sinensis Pers. into his mouth. Isovitexin, the most abundant flavonoid in the leaves of Celtis sinensis ${ }^{16}$, is a widely found natural carbon glycoside flavonoid. Isovitexin has various pharmacological activities, such as antineoplastic ${ }^{17}$, antioxidant ${ }^{18}$, and neurological protective effects ${ }^{19}$. This compound has also shown anti-inflammatory efficacy against human diseases ${ }^{20}$. It has been reported that isovitexin inhibits the MAPK and NF-KB pathways in macrophages in acute lung injury ${ }^{20}$. In lymphocytes, a number of ACDassociated cytokines are dependent on JAK-STAT signaling, and antigen presentation is dependent on MAPK signaling for the effects on cellular transcription and activation. In this study, a contact-

hypersensitivity mouse model induced by GA was established to reveal the mechanisms underlying the anti-inflammatory effect of isovitexin. In summary, this study provides supporting data for isovitexin ameliorating GA-induced allergic contact dermatitis.

\section{Meterials And Methods \\ 2.1 Reagents}


Isovitexin (chemical structure is shown in Fig. 2A,CAS No. 38953-85-4, purity:98.01\%) was obtained from Mansite Biotechnology, ChengDu, China) was dissolved in 100\% DMSO at a concentration of $100 \mathrm{mM}$ as a stock solution and diluted test concentration with culture medium before each experiment. Celtis sinensis Pers. leaves were collected from GuiZhou, China. The concentration of final DMSO did not extend $0.1 \%$ throughout the trail. Ginkgolic acids was purchased from Jingzhu Medical Technology (Nanjing, China). The Annexin V-FITC/PI apoptosis kit and ELISA kits for murine (TNF-a, IFN-y, IL-2, IL17A) were purchased from MultiSciences (Lianke) Biotech Co., Ltd. (Hangzhou, China). SHP099, the SHP2 inhibitor, purchased from Selleckchem. Concanavalin A (Con A), MTT, Freund's Adjuvant Complete (FAC) and Dexamethasone (Dex) were purchased from Sigma-Aldrich (St Louis, MO). Antibodies against phospho-STAT3 (Tyr705), phospho-AKT (Ser473), phospho-Ikba (Ser32), phospho-P38 (Thr180/Tyr182), phospho-JNK (Thr183/Tyr185), phospho-ERK1/2 (Thr 202/Tyr 204), Caspase-3, Caspase-8, Cleaved Caspase-3 (Asp175), Cleaved Caspase-8 (Asp387), Cleaved PARP (Asp214) and P65 were purchased from Cell Signal Technology (Beverly, MA). Antibodies against phospho-SHP2 (Tyr 542) was purchased from Abcam (Cambridge, UK). Anti- $\beta$-actin was purchased from Proteintech Group (Wuhan, China).

\subsection{Animal}

Female ICR mice and BALB/c mice, 18-23 g, 6-8 weeks old, were obtained from the Experimental Animal Center of Yangzhou University (Yangzhou, China). The mice were maintained in plastic cages with free access to eat food and drink water, temperature kept at $21 \pm 2^{\circ} \mathrm{C}$ and kept on a $12 \mathrm{~h}$ light/dark cycle. Animal welfare and experimental procedures were subjected to the Guide for the Care and Use of Laboratory Animals (National Institutes of Health, USA), and the study protocol was approved by the Animal Care and Protection Committee of Nanjing University-Gulou Hospital (SYXK 2004-0013). The authors confirmed that all animals received human care and all animal experiments were performed in accordance with the relevant guidelines and regulations. All the authors complied with the ARRIVE guidelines experiments.

Experimental design for GA-induced contact hypersensitivity is shown in Fig. 1A. On the first day (day 0), female ICR mice were sensitized with FAC emulsified GA (GA/FAC, $1 \mathrm{mg} / \mathrm{ml}, 100 \mu \mathrm{l}$ ) in the right flank by subcutaneous injection. On Day 6 and day 13, mice were sensitized with FAC emulsified GA (GA/FAC, 1 $\mathrm{mg} / \mathrm{ml}, 200 \mu \mathrm{l}$ ) in the back by subcutaneous injection of multipoints. On the last day (day 20), mice were challenged on their left ears with GA/FAC $(10 \mathrm{mg} / \mathrm{ml}, 30 \mu \mathrm{l}) .24$ hours after the challenge, the ear thickness was measured with a digimatic micrometer. Ears' swelling was evaluated by the thickness difference between the left and right. Mice in normal group were normally sensitized with FAC and challenged with olive oil without GA. CLE $(100,200 \mathrm{mg} / \mathrm{kg}$, intragastrically) or isovitexin $(10,20 \mathrm{mg} / \mathrm{kg}$, intraperitoneally) or dexamethasone $(0.5 \mathrm{mg} / \mathrm{kg}$, intraperitoneally) was administered once a day from day 6 to day 20. Mice in the normal group and model group were given saline as control.

\subsection{Cell culture and proliferation assay}

T cells, isolated from female Balb/c mice Lymph nodes, were cultured in 96-well plates in 1640 medium at the density of $5 \times 10^{6}$ cells/well and stimulated with $5 \mu \mathrm{g} / \mathrm{ml}$ of Con A for $48 \mathrm{~h}$ under a humidified $5 \%$ 
(v/v) $\mathrm{CO}_{2}$ atmosphere at $37^{\circ} \mathrm{C}$. MTT with concentration of $4 \mathrm{mg} / \mathrm{ml}$ dissolves in PBS, $20 \mu \mathrm{l}$ of MTT was added in each well $4 \mathrm{~h}$ before the end of incubation. Then culture media was removed and $200 \mu \mathrm{DMSO}$ was added to dissolve the crystals. Measuring the absorbance value at $540 \mathrm{~nm}$.

\subsection{Extraction of Celtis leaves}

The method of extraction followed with few modifications as described by Lee et al ${ }^{21}$. The air-dried leaves of Celtis sinensis were ground in a cutting mill and soaked with ethyl alcohol ( $25 \mathrm{~L}^{\prime} 3$, for $1.5 \mathrm{~h}$ each) at $70^{\circ} \mathrm{C}$. After the crude extract was dried under reduced pressure, a crude dark green residue was suspended in water with freeze-dried preservation.

\subsection{RT-PCR}

Total RNA was obtained from lymph node cells of mice, and reverse transcribed to cDNA. After cDNA was amplified by PCR, the expression of specific RNA was detected by $5 \%$ agarose gel electrophoresis. The primer sequences were used:

tnf-a forward CCCTCACACTCAGATCATCTTCT,

tnf-a reverse GCTACGACGTGGGCTACAG;

ifn-y forward GCCACGGCACAGTCATTGA

ifn-y reverse TGCTGATGGCCTGATTGTCTT;

il-2 forward GTGCTCCTTGTCAACAGCG,

il-2 reverse GGGGAGTTTCAGGTTCCTGTA;

il-17a forward TTTAACTCCCTTGGCGCAAAA,

il-17a reverse CTTTCCCTCCGCATTGACAC.

\subsection{Cytokine assay}

Cytokine levels were measured using ELISA kits from MultiSciences (Lianke) Biotech Co., Ltd. (Hangzhou, China) according to the manufacturer's instructions.

\subsection{Western blot analysis}

Cells isolated from lymph node were cultured in 6-well plates at a density of $1 \times 10^{7}$ cells/well in RPMI1640 medium and stimulated with Con A $(5 \mu \mathrm{g} / \mathrm{ml})$. Proteins lysed from cultured cells were separated by SDS-PAGE and electrophoreticically transferred onto PVDF membranes (Millipore, Bedford, MA). After treatment with blocking buffer in $5 \%$ BSA at RT for $1 \mathrm{~h}$, membranes were incubated with primary antibodies at $4^{\circ} \mathrm{C}$ overnight, and the secondary antibody incubation at RT for $2 \mathrm{~h}$. Protein content was detected by ECL luminescence method. 


\subsection{Histological analysis}

The $5 \mathrm{~mm}$ thickness of ear sections were obtained by formalin-fixed, paraffin-embedded and stained with hematoxylin and eosin. Histological parameter was following as described before: (1) the level of leukocyte infiltration and vascular congestion; (2) the erosion and anabrosis of epidermal cells; (3) affection of the other side of the ears ${ }^{22}$. We scored each of the histological assessment on a scale of 1 to 4 and the higher score means more serious inflammation.

\subsection{Molecular docking analysis}

The molecular docking analysis was conducted in Maestro v11.1 (Schrödinger, LLC) by the default protocols ${ }^{23}$. We prepared the ligand isovitexin and SHP2 protein (Protein Data Bank ID: 305x). The docking grid was generated based on the position of the tyrosine phosphatase SHP2 with the default protocol. Subsequently, glide docking was performed and induce-fit docking was conducted based on the results of glide docking

\subsection{Statistical analysis}

All Data were represented means \pm SEM from triplicate experiments performed in a parallel manner. Data were statistically compared and one-way analysis of variance ANOVA followed by Dunnett's test between the vehicle group and multiple dose groups. The level of significance was set at $P<0.05$.

\section{Results}

\subsection{Celtis sinensis leaf extract (CLE) protects mice from allergic contact dermatitis}

Celtis sinensis is employed as a folk medicine for treating inflammation, skin infections and other diseases ${ }^{24}$. To study the possibility of using Celtis sinensis to treat inflammation in GA-induced allergic contact dermatitis, a mouse model of GA-induced hypersensitive contact dermatitis was established. We stimulated the popliteal lymph nodes and the left ear of ICR mice by GA (Fig. 1A). Mice challenged by GA displayed definite inflammation, as indicated by splenomegaly and ear swelling, compared with the vehicle group.

Celtis sinensis leaf extract (investigational ingredient, CLE) and dexamethasone (positive control drug, Dex) were used to treat the degree of ear swelling. Notably, mice that received CLE exhibited significantly reduced susceptibility to GA-induced allergic contact dermatitis, as shown by the milder splenomegaly and ear swelling compared with the model group (Fig. 1B and C). Indeed, CLE did not decrease the body weight of mice, but it appeared in mice that received dexamethasone (Fig. 1D). Histopathologically, mice that received CLE displayed significantly alleviated leukocyte infiltration, epidermal anabrosis and affection damage compared with the vehicle group (Fig. 1E and F). Collectively, intragastric instillation of CLE confers protection from GA-induced allergic contact dermatitis in ICR mice. 


\subsection{Isovitexin, the main flavonoid in the leaves of Celtis sinensis, ameliorates GA-induced allergic contact dermatitis in mice}

Since isovitexin (Fig. 2A) is the predominant flavone of Celtis sinensis ${ }^{25}$, we further examined the possible role of isovitexin in dermal inflammation. Mice that received isovitexin exhibited ameliorative ear swelling and splenomegaly compared with the model group (Fig. 2B and C). Meanwhile, consistent with the CLE experiments, isovitexin did not show body weight loss, suggesting that compared with dexamethasone, isovitexin displayed significant anti-inflammatory function without serious side effects (Fig. 2D). Histopathologically, mice that received isovitexin displayed directly reduced leukocyte chemotaxis and ameliorated proinflammatory cytokine release (Fig. 2E and F). Therefore, isovitexin, a natural flavone, exerts immunosuppressive effects in GA-induced allergic contact dermatitis

\subsection{Isovitexin inhibits T cell-mediated inflammation in mice with GA-induced allergic contact dermatitis}

Stimulation with GA also exacerbated the release of inflammatory cytokines (TNF-a, IFN- $y$, IL-2, and IL$17 \mathrm{~A}$ ) in serum. The upregulation of these T cell-specific cytokines indicates that GA-induced allergic contact dermatitis mainly triggers inflammatory activation of $\mathrm{T}$ cells rather than macrophage-mediated innate inflammation. The anti-inflammatory effects of isovitexin were presumably attributed to a decrease in T cell-specific cytokines in serum (Fig. 3A). We then evaluated the mRNA level of T cellassociated cytokines in popliteal lymph nodes. Compared with inflamed dermatitis mice, the contents of tnf-a, ifn-y, il-2, and il-17a were significantly lower in mice that received isovitexin (Fig. 3B and C). Moreover, we observed that proapoptotic proteins (cleaved caspase-3 and cleaved PARP) were activated and that proliferation proteins (phosphor-AKT and phospho-ERK1/2) were inhibited in isovitexin-treated T cells from allergic mice (Fig. 3D and E). Taken together, these data clearly demonstrate that isovitexin may inhibit $\mathrm{T}$ cell-mediated inflammatory responses in dermatitis.

\subsection{Isovitexin inhibits the proliferation and promotes apoptosis of Con A-activated T cells in vitro}

The above findings prompted us to suppose that isovitexin diminished $\mathrm{T}$ cell proinflammatory activities in response to GA stimulation. Furthermore, we used Con A-activated T cells to explore the mechanisms underlying the antagonizing effects of isovitexin on metabolic disorders. Con $A$ is a plant lectin that induces the mitogenic activity of $\mathrm{T}$ lymphocytes and increases the production of inflammatory cytokines such as IL-2, TNF-a and IFN- ${ }^{26}$. The MTT assay was used to assess cell viability. As shown in Fig. 4B, Con $A(5 \mu \mathrm{g} / \mathrm{ml})$ strongly promoted $\mathrm{T}$ cell proliferation. In addition, cell culture with the addition of 0-100 $\mu \mathrm{M}$ isovitexin was not toxic to naïve $\mathrm{T}$ cells, but it inhibited the proliferation of Con A-activated T cells 
(Fig. 4A and B). On the other hand, isovitexin triggered apoptosis of Con A-activated T cells, as analyzed by the Annexin V/PI staining assay (Fig. 4C). The percentages of early apoptotic T cells significantly increased with different doses of isovitexin after $24 \mathrm{~h}$ of incubation. To define the pathway of apoptosis, western blotting was used to analyze the cleavage of poly (ADP-ribose) polymerase (PARP) and caspase. Strong cleavage of PARP together with activation of caspase-3 and -8 were observed in the Con Aactivated T cells treated with isovitexin, which is consistent with the results of animal experiments (Fig. $4 \mathrm{D}$ and $\mathrm{E}$ ). These observations indicate that isovitexin inhibits the proliferation of Con A-activated T cells by promoting apoptosis.

\subsection{Isovitexin inhibits the production of proinflammatory cytokines in Con A-activated T cells}

Numerous apoptotic cells have been shown to inhibit proinflammatory cytokine production, preventing chronic inflammation ${ }^{27}$. For this claim, we examined whether isovitexin is linked with the production of proinflammatory cytokines, including TNF-a, IFN-y, IL-2 and IL-17A. ELISA was performed to measure the release of cytokines in the culture supernatant, and RT-PCR was carried out to measure the expression of these cytokines from Con A-activated T cells (Fig. 5A, B and C). Interestingly, at a concentration of 100 $\mu \mathrm{M}$, isovitexin significantly reduced the levels of proinflammatory cytokines (TNF-a, IFN- $\gamma$, IL-2 and IL17A) at both the mRNA and protein levels.

\subsection{The MAPK and STAT signaling pathways are regulated by isovitexin in Con A-activated T cells}

The MAPK and STAT signaling pathways govern the expression of most proinflammatory genes ${ }^{28,29}$. To understand how isovitexin modulates inflammatory responses in T cells, we examined the relationship between isovitexin and these pathways. Mechanistically, T cells treated with $100 \mu \mathrm{M}$ isovitexin exhibited markedly reduced phosphorylation of proteins such as P38, JNK, and ERK1/2 in Con A-induced T cells, which are the central kinases in the MAPK signaling pathway that cause inflammation. On the other hand, isovitexin dose-dependently decreased the level of IKB phosphorylation. The kinase is activated by a highly diverse group of extracellular signals, including inflammatory cytokines, growth factors, and chemokines. Unexpectedly, isovitexin did not affect the expression of p65 in whole cell lysate, and whether p65 is in the core needs to be further proven. Western blotting was also used to explore whether isovitexin decreased the phosphorylation of STAT3, STAT6, and SHP2, which play important roles in the proliferation and differentiation of T cells. Thus, isovitexin serves as a negative regulator of the MAPK and STAT signaling pathways (Fig. 6A and B).

\subsection{Molecular docking analysis of the interaction between isovitexin and SHP2 protein}


Next, we sought to determine the molecular mechanisms by which isovitexin modulates the MAPK and STAT signaling pathways in Con A-activated T cells. We first tested whether isovitexin might interact with SHP2. The interaction between the SHP2 protein and isovitexin was demonstrated by molecular docking analysis. As shown in the figure, there is a certain intensity of interaction between SHP2 and isovitexin, and the best induced-fit docking score is $-5.414 \mathrm{kcal} / \mathrm{mol}$, where isovitexin can insert into the active domain of SH2 kinase and interact by hydrogen bonding and $\pi-\pi$ interactions (Fig. $6 \mathrm{C}$ ). The docking results suggest that there is obvious $\pi-\pi$ conjugation between TYR279, the $B$ ring and the $C$ ring of isovitexin. There may be two hydrogen bond interactions between SHP2 and isovitexin: one formed between the ASN281 residue and 4'-OH on the C ring of isovitexin, and the other formed between GLN and the carbonyl group on the $B$ ring of isovitexin. Indeed, the A ring of isovitexin forms seven kinds of hydrogen bonds with SHP2 with ASP425, LYS366, AGR465, TRP423 and GLY427, which confer stability to the docking conformation (Fig. 6D).

\subsection{The effects of isovitexin on Con A-activated T cells can be reversed by the SHP2-specific inhibitor SHP099}

SHP099, a selective SHP2 inhibitor, binds to protein tyrosine phosphatase domains, inhibiting SHP2 activity through an allosteric mechanism ${ }^{30}$. We investigated whether isovitexin suppressed the release of cytokines by regulating SHP2 in Con A-activated T cells, and the effects were examined in SHP099treated cells. The results showed that the inhibitory effects of isovitexin on $\mathrm{T}$ cell proliferation and proinflammatory cytokine production were partially reversed by SHP099 (Fig. 7A and B). Moreover, the regulation of the expression of p-STAT3 and p-STAT6 was partially reversed by SHP099 as well in T cells incubated with isovitexin (Fig. 7C and D). In summary, our study proved that isovitexin restrains p-SHP2 and controls dermatitis inflammation (Fig. 8).

\section{Discussion}

Allergic contact dermatitis is a skin disease caused by environmental or occupational allergens. As a general concept of the antigen presentation process in the sensitization phase of ACD, allergens activate innate immunity through keratinocyte release of proinflammatory cytokines and chemokines to recruit $T$ cells. Hapten-specific T cells are guided to inflammatory sites and produce cytokines, such as TNF-a, IFN$y$ and IL-17A. In turn, these cytokines then stimulate skin-resident cells, which lead to further recruitment of $T$ cells and induce an inflammatory cascade ${ }^{31,32}$. Indeed, dysregulation of the skin immune system occurs in nearly all ACD cases, which highlights the importance of appropriate immune regulation in preventing ACD. However, studies of contact-hypersensitivity mouse models have mostly used synthetic experimental allergens, such as DNFB. Different allergens cause widely divergent immune responses, resulting in the eventual failure of the therapeutic strategies for ACD. We therefore optimized a mouse model of GA-induced ACD to identify inflammation and ear swelling. We identified a critical role of 
proinflammatory cytokines such as TNF-a, IFN-y, IL-2 and IL-17A in skin inflammation in this model and revealed that these cytokines may be regulated by SHP2 in vitro.

As an environmental allergen, GA-induced ACD is usually treated with NSAIDs or immunosuppressive drugs, and long-term use may result in serious side effects, including effects on the gastrointestinal tract and infection susceptibility ${ }^{33}$. In this context, new pharmacological strategies are being sought, such as resolution of inflammation with fewer side effects. In the present study, we have provided proof that CLE, especially isovitexin, may dampen proinflammatory signaling and the clearance of proinflammatory mediators to attenuate inflammation. In conclusion, isovitexin acts as an inflammatory inhibitor to ameliorate GA-induced ACD.

Isovitexin is the most abundant flavone in the leaves of Celtis sinensis. It has anti-inflammatory pharmacological properties. In a previous study, isovitexin attenuated the LPS-induced phosphorylation of all three MAPKs, reduced NF-KB activation and promoted M2 polarization in macrophages ${ }^{20,34}$. However, few studies targeting the anti-inflammatory effects of $\mathrm{T}$ lymphocytes by isovitexin treatment have been reported. To reveal the regulatory effects of isovitexin on ACD, which is characterized by the Th1 response ${ }^{35}$, we used T cells from mouse lymph node cells under Con A stimulation. In this study, we found that isovitexin dose-dependently upregulated apoptosis and suppressed the cytokines TNF-a, IFN- $\gamma$, IL-2 and IL-17A. This result is consistent with animal experiments, indicating that isovitexin exerts an immunomodulatory effect when facing an inflammatory challenge.

To further reveal the underlying mechanisms of isovitexin on T cell apoptosis and signaling pathways. We further examined the effects of isovitexin on cleaved caspase-3, cleaved caspase-8, MAPK signaling and STAT signaling in activated T cells. In this study, we have provided several lines of evidence that suggest that cleaved caspase- 3 and cleaved caspase- 8 are significantly enhanced by isovitexin treatment in a dose-dependent manner. These cleaved proteins lead to increased apoptosis. MAPK signaling and STAT signaling, along with countless studies linking to inflammatory pathologies, provide the rationale for applying potent inhibitors in the treatment of immune-system-mediated diseases ${ }^{29,36}$. Our research result is somewhat consistent with a previous report in which isovitexin normalized the phosphorylation of all three MAPKs and reduced NF-KB activation and the STAT signaling pathway. In addition, isovitexin dampens proinflammatory signaling and promotes the resolution of inflammation.

SHP2, a nonreceptor protein tyrosine phosphatase, was the first reported oncogenic tyrosine phosphatase and has attracted much attention. The function of SHP2 was reported to regulate cell survival and proliferation primarily through activation of the RAS-ERK signaling pathway and to mediate the immune checkpoint pathways ${ }^{37}$. Moreover, SHP2 is an important mediator in lupus erythematosus, ERK/MAPK signaling normalization and reduced production of IFN- $\gamma$ and IL-17a cytokines involved in inflammation can occur by directly inhibiting SHP2 ${ }^{38}$. Meanwhile, SHP2 is required for full activation of the JAK/STAT pathway, a major signaling cascade in inflammation ${ }^{39}$. SHP2 has been characterized as a positive regulator of JAK2/STAT3 signaling in rheumatoid arthritis diseases ${ }^{40}$. Here, molecular docking showed that isovitexin may bind to the PTP domain with hydrogen bonding and $\pi-\pi$ interactions. Western 
blotting experiments suggested that isovitexin normalized Src-homology 2 domain-containing phosphatase tyrosine (Y542) phosphatase, which upregulates phosphatase activity ${ }^{41}$. Indeed, downregulated SHP2 reduces the downstream MAPK and STAT signaling pathways, which decreases the level of proinflammatory cytokine release and ameliorates ACD. It also prevents the T cell-decreased MAPK signaling, which would cause autoreactivity and autoimmunity ${ }^{42}$. In summary, isovitexin blockade of SHP2 may be a novel and effective therapy for the treatment of patients with GA-induced ACD.

SHP099, an inhibitor that binds to the allosteric site of SHP2 and stabilizes the closed form of SHP2 by interacting with the N-SH2 and PTP domains, has been used to provide several lines of evidence, which suggested functional expression and a physiological signaling role of SHP2 in Con A-active T cells. First, the Annexin V/PI staining results showed that T cells treated with isovitexin and SHP099 had an increased proportion of living cells versus the isovitexin group alone. These results indicated that isovitexin promotes T lymphocyte apoptosis by downregulating SHP2 activation. Moreover, SHP099 also reversed the inhibitory effects of isovitexin on MAPK and STAT signaling. Our results indicate that isovitexin exerts SHP2-dependent inhibitory effects in Con A-activated T cells.

In summary, our study demonstrates that isovitexin from Celtis sinensis is a potential therapeutic agent against GA-induced allergic contact dermatitis. The MAPK and STAT signaling pathways can be regulated by isovitexin, and SHP2 may be a potential anti-inflammatory target of isovitexin in T cells. Isovitexin can be used to solve anti-inflammatory problems induced by GA.

\section{Abbreviations}

GA Ginkgolic acids

CLE Celtis sinensis Pers. leaf extract

IsoV Isovitexin

ACD Allergic contact dermatitis

SHP2 SH2 domain-containing protein-tyrosine phosphatase-2

MAPK Mitogen-activated protein kinase

STAT Signal transducer and activator of transcription

Con A Concanavalin A

FAC Freund's Adjuvant Complete

TNF-a Tumor necrosis factor-a

IL-2 Interleukin-2

IL-17A Interleukin-17A

IFN-y Interferon $\mathrm{Y}$ 


\section{Declarations}

\section{Conflict of Interest}

There are no conflict of interest.

\section{Author Contributions}

Conceptualization, X.F. L.Z; Methodology, Y.Z., Z.Q., L.W.; Writing - Original Draft Preparation, Y.Z, Writing

- Review \& Editing, W.W; Supervision, F.C.; Funding Acquisition X.F., L.Z.

\section{Acknowledgments}

This work was supported by the National Natural Science Foundation of China (31600465), the Natural Science Foundation of the Jiangsu Province (BK20160929), and Project supported by the Natural Science Foundation of the Jiangsu Higher Education Institutions of China (16KJB220002).

\section{References}

1. Omidkhoda, S. F., Razavi, B. M. \& Hosseinzadeh, H. Protective effects of Ginkgo biloba L. against natural toxins, chemical toxicities, and radiation: A comprehensive review. Phytother Res. 33, 28212840 https://doi.org/10.1002/ptr.6469 (2019).

2. Zhou, G. et al. Optimization of Ultrasound-Assisted Extraction Followed by Macroporous Resin Purification for Maximal Recovery of Functional Components and Removal of Toxic Components from Ginkgo biloba Leaves. Biomed Res Int 2018, 4598067, doi:10.1155/2018/4598067 (2018).

3. Miwa, H., lijima, M., Tanaka, S. \& Mizuno, Y. Generalized convulsions after consuming a large amount of gingko nuts. Epilepsia. 42, 280-281 https://doi.org/10.1046/j.1528-1157.2001.33100.x (2001).

4. Qian, Y. et al. Metabolic profiling of the hepatotoxicity and nephrotoxicity of Ginkgolic acids in rats using ultra-performance liquid chromatography-high-definition mass spectrometry. Chem Biol Interact. 273, 11-17 https://doi.org/10.1016/j.cbi.2017.05.020 (2017).

5. Mei, N. et al. Review of Ginkgo biloba-induced toxicity, from experimental studies to human case reports. J Environ Sci Health C Environ Carcinog Ecotoxicol Rev. 35, 1-28 https://doi.org/10.1080/10590501.2016.1278298 (2017).

6. Hotta, E., Tamagawa-Mineoka, R. \& Katoh, N. Allergic contact dermatitis due to ginkgo tree fruit and leaf. Eur J Dermatol. 23, 548-549 https://doi.org/10.1684/ejd.2013.2102 (2013).

7. van Beek, T. A. \& Montoro, P. Chemical analysis and quality control of Ginkgo biloba leaves, extracts, and phytopharmaceuticals. J Chromatogr A. 1216, 2002-2032 https://doi.org/10.1016/j.chroma.2009.01.013 (2009). 
8. Fang, X. et al. Effects of beta-glucosidase and alpha-rhamnosidase on the Contents of Flavonoids, Ginkgolides, and Aroma Components in Ginkgo Tea Drink. Molecules. 24, https://doi.org/10.3390/molecules24102009 (2019).

9. Fransen, H. P., Pelgrom, S. M., Stewart-Knox, B., de Kaste, D. \& Verhagen, H. Assessment of health claims, content, and safety of herbal supplements containing Ginkgo biloba. Food Nutr Res. 54, https://doi.org/10.3402/fnr.v54i0.5221 (2010).

10. Campos, D., Navarro, S., Llamas-Gonzalez, Y. Y., Sugasti, M. \& Gonzalez-Santamaria, J. Broad Antiviral Activity of Ginkgolic Acid against Chikungunya, Mayaro, Una, and Zika Viruses. Viruses. 12, https://doi.org/10.3390/v12040449 (2020).

11. Qi, Q. M. et al. Ginkgolic acids induce HepG2 cell death via a combination of apoptosis, autophagy and the mitochondrial pathway. Oncol Lett. 15, 6400-6408 https://doi.org/10.3892/ol.2018.8177 (2018).

12. Wang, M. et al. High-resolution gas chromatography/mass spectrometry method for characterization and quantitative analysis of ginkgolic acids in Ginkgo biloba plants, extracts, and dietary supplements. J Agric Food Chem. 62, 12103-12111 https://doi.org/10.1021/jf503980f (2014).

13. Boelman, D. J. \& Emergency Treating poison ivy, oak, and sumac. Am J Nurs. 110, 49-52 https://doi.org/10.1097/01.NAJ.0000377690.87350.36 (2010).

14. Han, E. J., Park, H. L. \& Kim, S. H. Allergic Reaction to Ginkgo Nut on FDG PET/CT. Clin Nucl Med. 41, 716-717 https://doi.org/10.1097/RLU.0000000000001276 (2016).

15. Ude, C., Schubert-Zsilavecz, M. \& Wurglics, M. Ginkgo biloba extracts: a review of the pharmacokinetics of the active ingredients. Clin Pharmacokinet. 52, 727-749 https://doi.org/10.1007/s40262-013-0074-5 (2013).

16. Zehrmann, N., Zidorn, C. \& Ganzera, M. Analysis of rare flavonoid C-glycosides in Celtis australis L. by micellar electrokinetic chromatography. J Pharm Biomed Anal. 51, 1165-1168 https://doi.org/10.1016/j.jpba.2009.11.028 (2010).

17. Cao, X. et al. Isovitexin reduces carcinogenicity and stemness in hepatic carcinoma stem-like cells by modulating MnSOD and FoxM1. J Exp Clin Cancer Res. 38, 264 https://doi.org/10.1186/s13046-0191244-6 (2019).

18. Liu, S., Zhang, X. \& Wang, J. Isovitexin protects against cisplatin-induced kidney injury in mice through inhibiting inflammatory and oxidative responses. Int Immunopharmacol. 83, 106437 https://doi.org/10.1016/j.intimp.2020.106437 (2020).

19. Liu, B. et al. Corrigendum: Isovitexin-Mediated Regulation of Microglial Polarization in Lipopolysaccharide-Induced Neuroinflammation via Activation of the CaMKKbeta/AMPK-PGC1alpha Signaling Axis. Front Immunol. 11, 41 https://doi.org/10.3389/fimmu.2020.00041 (2020).

20. Lv, H. et al. Isovitexin Exerts Anti-Inflammatory and Anti-Oxidant Activities on LipopolysaccharideInduced Acute Lung Injury by Inhibiting MAPK and NF-kappaB and Activating HO-1/Nrf2 Pathways. Int J Biol Sci. 12, 72-86 https://doi.org/10.7150/ijbs.13188 (2016). 
21. Lee, S. et al. Bioactivity-Guided Isolation of Anti-Inflammatory Constituents of the Rare Mushroom Calvatia nipponica in LPS-Stimulated RAW264.7 Macrophages. Chem Biodivers. 15, e1800203 https://doi.org/10.1002/cbdv.201800203 (2018).

22. Luo, Q. et al. Erlotinib inhibits T-cell-mediated immune response via down-regulation of the c-Raf/ERK cascade and Akt signaling pathway. Toxicol Appl Pharmacol. 251, 130-136 https://doi.org/10.1016/j.taap.2010.12.011 (2011).

23. Wang, J. et al. Reversal Effect of ALK Inhibitor NVP-TAE684 on ABCG2-Overexpressing Cancer Cells. Front Oncol. 10, 228 https://doi.org/10.3389/fonc.2020.00228 (2020).

24. Rojas-Bedolla, E. I. et al. Chemical characterization, pharmacological effects, and toxicity of an ethanol extract of Celtis pallida Torr. (Cannabaceae) aerial parts. J Ethnopharmacol. 219, 126-132 https://doi.org/10.1016/j.jep.2018.03.014 (2018).

25. Ota, A. et al. Nutritional, antioxidative, and antimicrobial analysis of the Mediterranean hackberry (Celtis australis L.). Food Sci Nutr. 5, 160-170 https://doi.org/10.1002/fsn3.375 (2017).

26. Shinohara, Y. \& Tsukimoto, M. Adenine Nucleotides Attenuate Murine T Cell Activation Induced by Concanavalin A or T Cell Receptor Stimulation. Front Pharmacol. 8, 986 https://doi.org/10.3389/fphar.2017.00986 (2017).

27. Voll, R. E. et al. Immunosuppressive effects of apoptotic cells. Nature. 390, 350-351 https://doi.org/10.1038/37022 (1997).

28. Huang, P., Han, J. \& Hui, L. MAPK signaling in inflammation-associated cancer development. Protein Cell. 1, 218-226 https://doi.org/10.1007/s13238-010-0019-9 (2010).

29. Villarino, A. V., Kanno, Y. \& O'Shea, J. J. Mechanisms and consequences of Jak-STAT signaling in the immune system. Nat Immunol. 18, 374-384 https://doi.org/10.1038/ni.3691 (2017).

30. Padua, R. A. P. et al. Mechanism of activating mutations and allosteric drug inhibition of the phosphatase SHP2. Nat Commun. 9, 4507 https://doi.org/10.1038/s41467-018-06814-w (2018).

31. Honda, T., Egawa, G., Grabbe, S. \& Kabashima, K. Update of immune events in the murine contact hypersensitivity model: toward the understanding of allergic contact dermatitis. J Invest Dermatol. 133, 303-315 https://doi.org/10.1038/jid.2012.284 (2013).

32. Leonard, A. \& Guttman-Yassky, E. The Unique Molecular Signatures of Contact Dermatitis and Implications for Treatment. Clin Rev Allergy Immunol. 56, 1-8 https://doi.org/10.1007/s12016-0188685-0 (2019).

33. Rosa, S. I., Rios-Santos, F., Balogun, S. O. \& Martins, D. T. Vitexin reduces neutrophil migration to inflammatory focus by down-regulating pro-inflammatory mediators via inhibition of p38, ERK1/2 and JNK pathway. Phytomedicine. 23, 9-17 https://doi.org/10.1016/j.phymed.2015.11.003 (2016).

34. Liu, B. et al. Isovitexin-Mediated Regulation of Microglial Polarization in Lipopolysaccharide-Induced Neuroinflammation via Activation of the CaMKKbeta/AMPK-PGC-1alpha Signaling Axis. Front Immunol. 10, 2650 https://doi.org/10.3389/fimmu.2019.02650 (2019).

35. Owen, J. L., Vakharia, P. P. \& Silverberg, J. I. The Role and Diagnosis of Allergic Contact Dermatitis in Patients with Atopic Dermatitis. Am J Clin Dermatol. 19, 293-302 https://doi.org/10.1007/s40257- 
017-0340-7 (2018).

36. Yahfoufi, N., Alsadi, N., Jambi, M. \& Matar, C. The Immunomodulatory and Anti-Inflammatory Role of Polyphenols. Nutrients. 10, https://doi.org/10.3390/nu10111618 (2018).

37. Chen, Y. N. et al. Allosteric inhibition of SHP2 phosphatase inhibits cancers driven by receptor tyrosine kinases. Nature. 535, 148-152 https://doi.org/10.1038/nature18621 (2016).

38. Wang, J. et al. Inhibition of SHP2 ameliorates the pathogenesis of systemic lupus erythematosus. $J$ Clin Invest. 126, 2077-2092 https://doi.org/10.1172/JCl87037 (2016).

39. Frankson, R. et al. Therapeutic Targeting of Oncogenic Tyrosine Phosphatases. Cancer Res. 77, 5701-5705 https://doi.org/10.1158/0008-5472.CAN-17-1510 (2017).

40. Ganesan, R. \& Rasool, M. Interleukin 17 regulates SHP-2 and IL-17RA/STAT-3 dependent Cyr61, IL-23 and GM-CSF expression and RANKL mediated osteoclastogenesis by fibroblast-like synoviocytes in rheumatoid arthritis. Mol Immunol. 91, 134-144 https://doi.org/10.1016/j.molimm.2017.09.003 (2017).

41. Jiang, L., Xu, W., Chen, Y. \& Zhang, Y. SHP2 inhibitor specifically suppresses the stemness of KRASmutant non-small cell lung cancer cells. Artif Cells Nanomed Biotechnol. 47, 3231-3238 https://doi.org/10.1080/21691401.2019.1646748 (2019).

42. Gorelik, G., Fang, J. Y., Wu, A., Sawalha, A. H. \& Richardson, B. Impaired T cell protein kinase C delta activation decreases ERK pathway signaling in idiopathic and hydralazine-induced lupus. $J$ Immunol. 179, 5553-5563 https://doi.org/10.4049/jimmunol.179.8.5553 (2007).

\section{Figures}


A

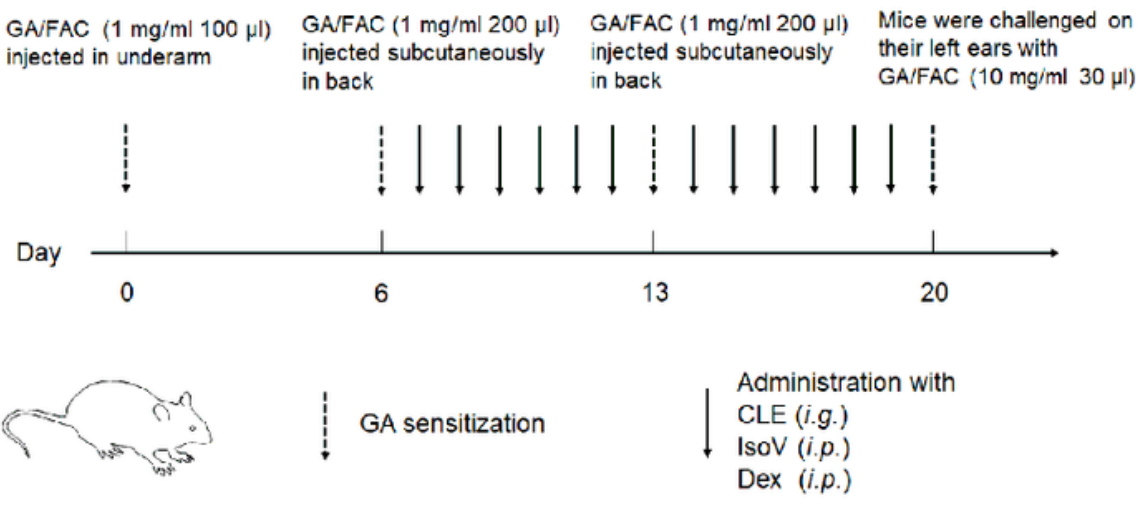

ICR mice (18-23g)

B

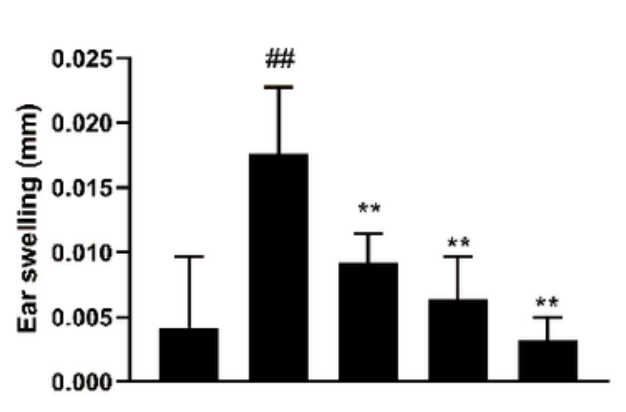

GA

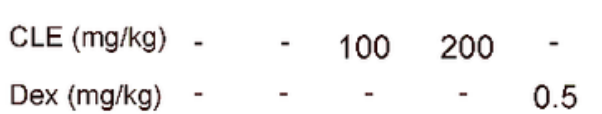

E
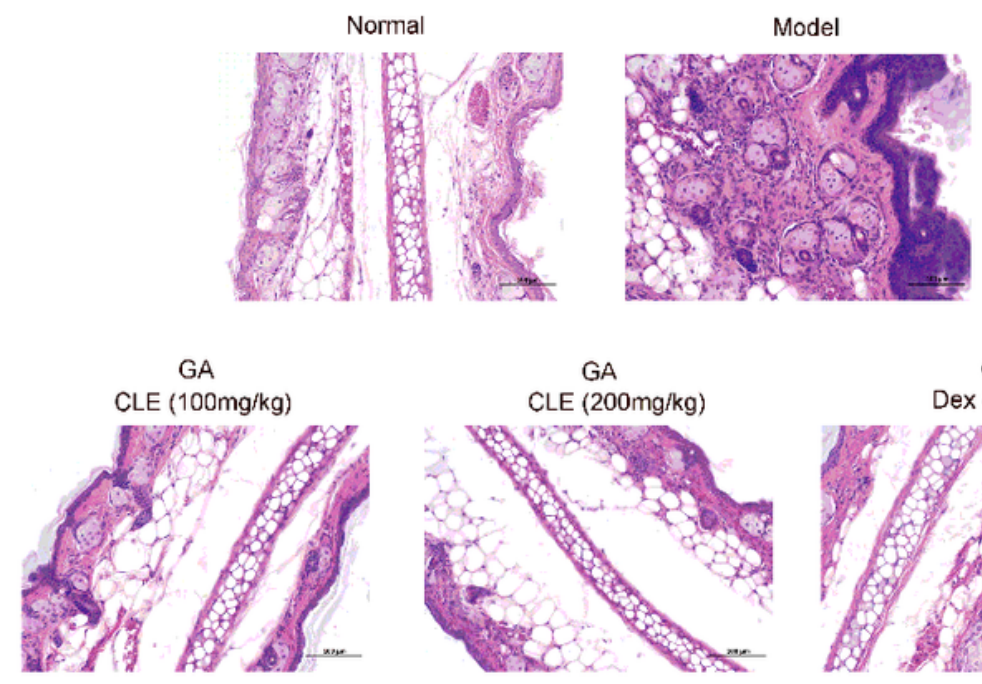

C
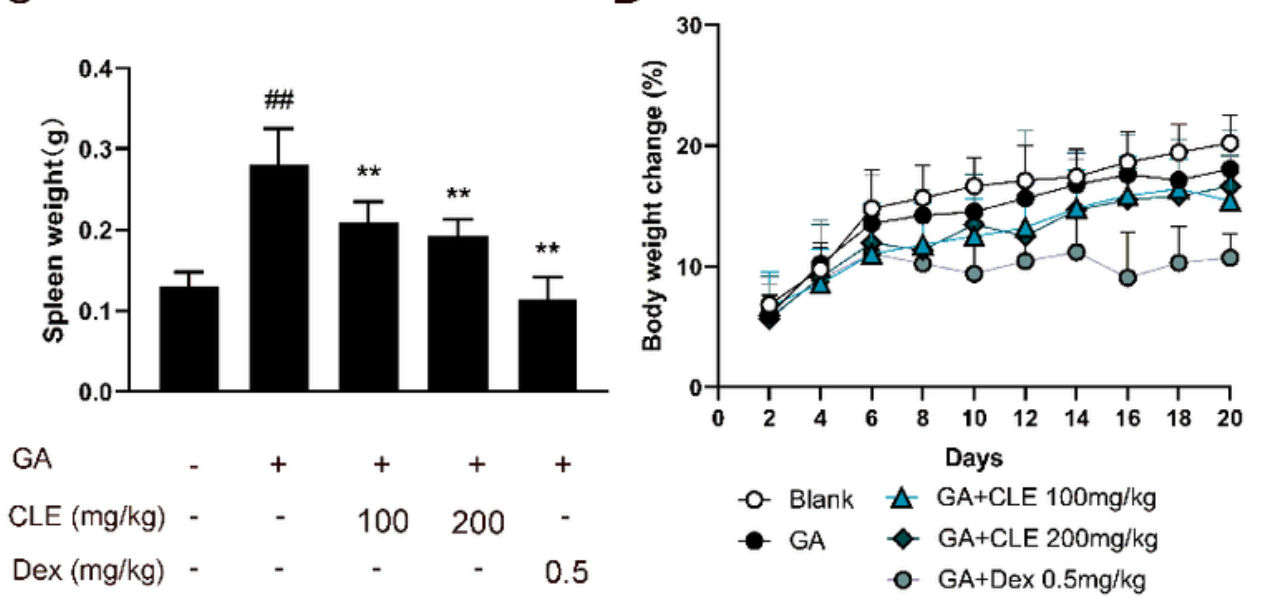

-O- Blank

$\triangle$ GA+CLE $100 \mathrm{mg} / \mathrm{kg}$

- GA

$\diamond \mathrm{GA}+\mathrm{CLE} 200 \mathrm{mg} / \mathrm{kg}$

o- GA+Dex $0.5 \mathrm{mg} / \mathrm{kg}$

$\mathrm{F}$

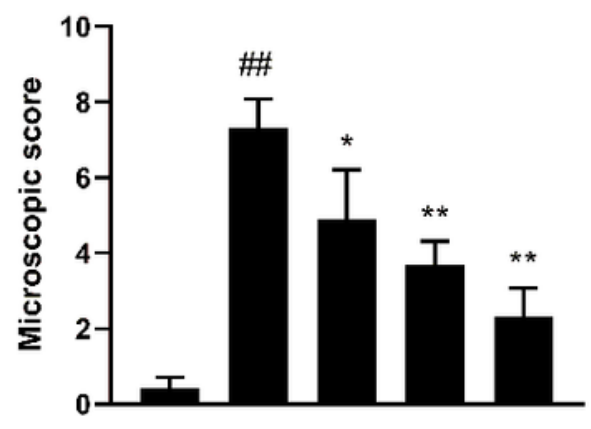

GA

$\operatorname{CLE}(\mathrm{mg} / \mathrm{kg}) \quad-\quad-100200$ -

$\operatorname{Dex}(\mathrm{mg} / \mathrm{kg})$

0.5

Figure 1

Celtis sinensis leaves Extract (CLE) ameliorates ginkgolic acids (GA)-induced contact dermatitis in mice. (A) The mouse model of GA-induced contact dermatitis, drugs were administered once a day from day 6 to day 20. (B)The mice were given CLE at 100 and $200 \mathrm{mg} / \mathrm{kg}$ respectively, and the ear swelling was measured $24 \mathrm{~h}$ after challenge at day 20. (C) Spleen weight was measured at day 20. (D) The body weight changes of mice in different groups. (E) Hematoxylin and eosin stain (original magnification 
200x) of ear tissue sections. Bars, $100 \mu \mathrm{m}$. (F) Ear histological scoring. Data represent means \pm SEM of eight mice. \#\#Pख0.01 vs vehicle group, *P囚0.05, **P囚0.01 vs model group.

A<smiles>O=c1cc(-c2ccc(O)cc2)oc2cc(O)c(C3O[C@H](CO)[C@@H](O)[C@H](O)[C@H]3O)c(O)c12</smiles>
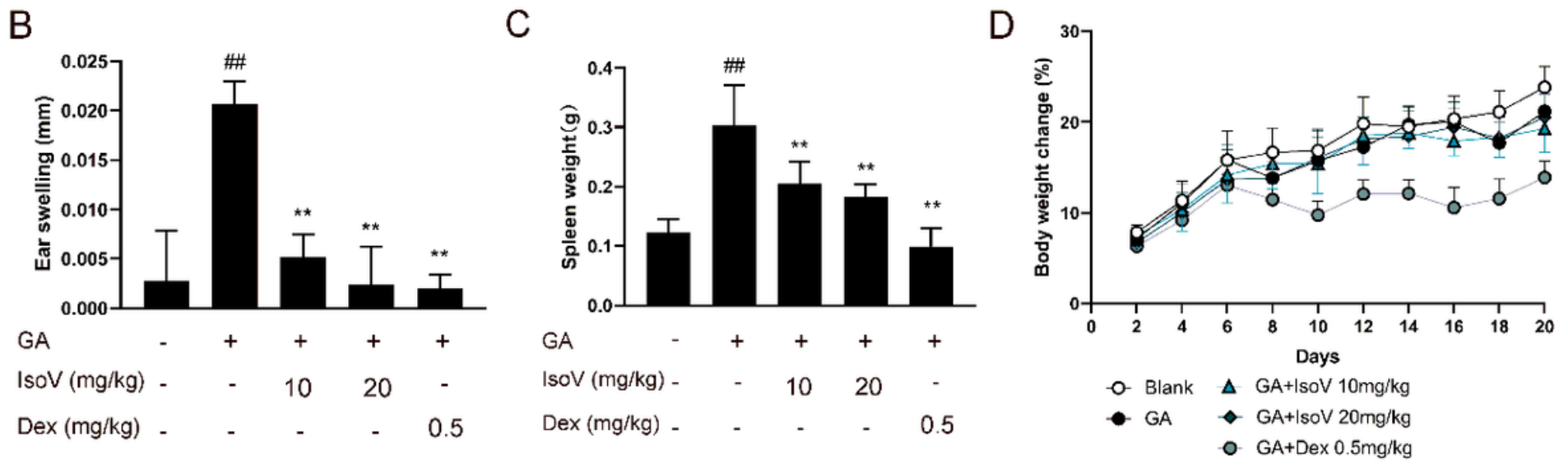

E
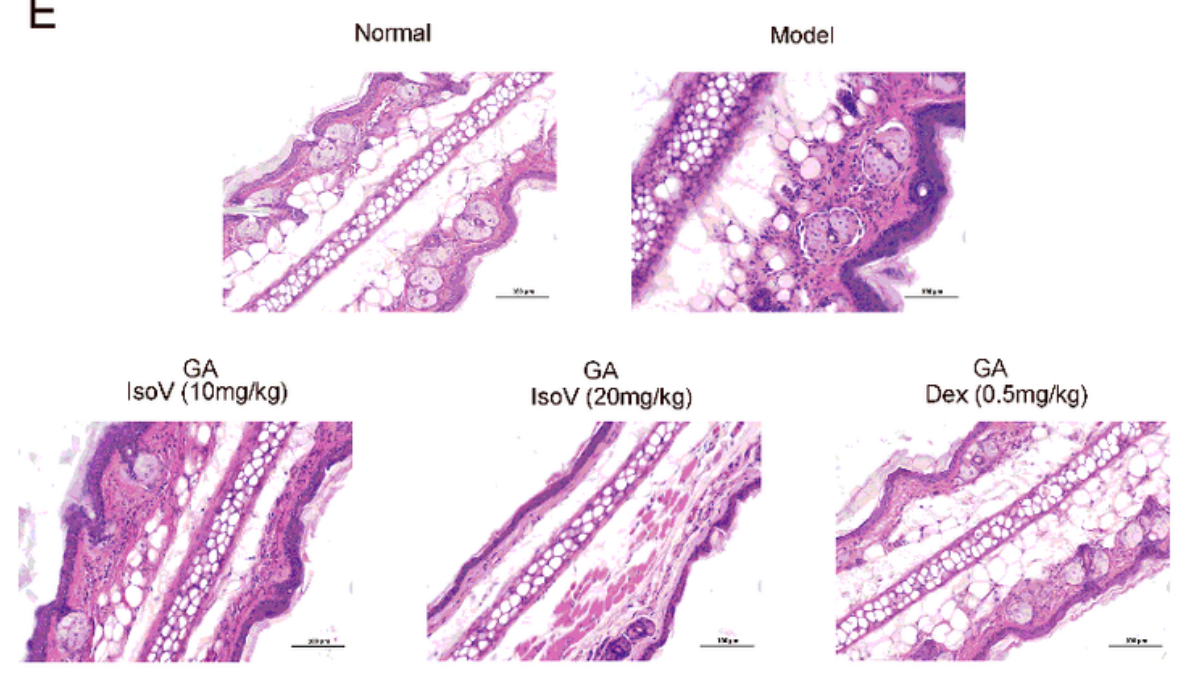

$\mathrm{F}$

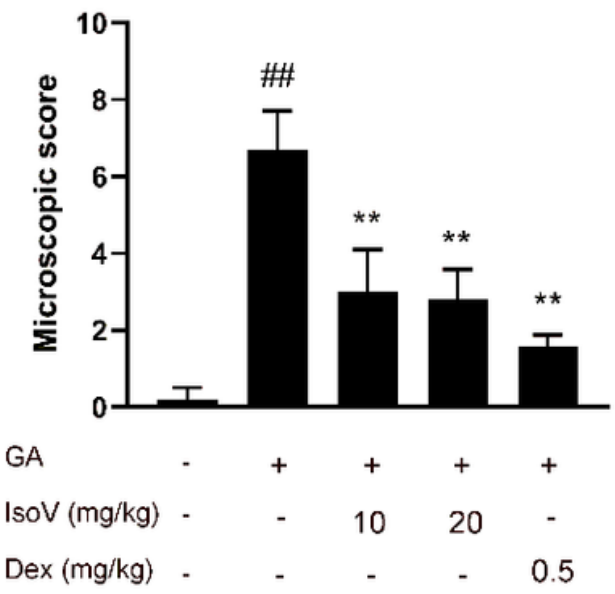

Figure 2

Isovitexin decreases the susceptibility of GA-induced contact dermatitis in mice. In the mouse model of GA-induced contact dermatitis, mice were given isovitexin, a main flavonoid compound from CEL, at 10 and $20 \mathrm{mg} / \mathrm{kg}$ respectively. (A) Chemical structural of isovitexin. (B) The ear swelling was measured at day 20. (C) Spleen weight was measured at day 20. (D) The body weight changes of mice in different groups. (E) Hematoxylin and eosin stain (original magnification 200x) of ear tissue sections. Bars, 100 
$\mu \mathrm{m}$. (F) Ear histological scoring. IsoV, isovitexin. Data represented means $\pm S E M$ of eight mice. \#\#P『0.01 vs vehicle group, *P $₫ 0.05, * * \mathrm{P} \otimes 0.01$ vs model group.
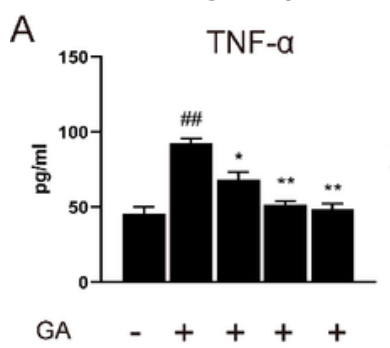

$\mathrm{IsoV}$
$(\mathrm{mg} / \mathrm{kg})$

Dex

$(\mathrm{mg} / \mathrm{kg}) \quad-\quad-\quad-0.5$

B

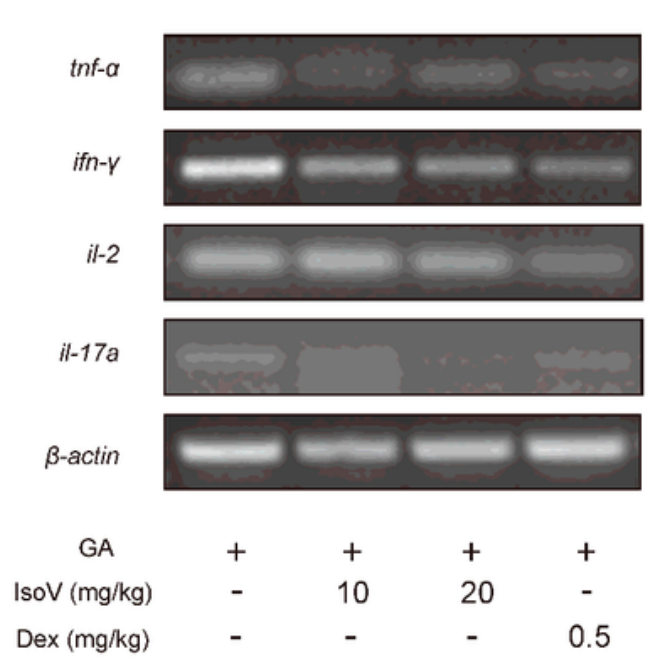

D
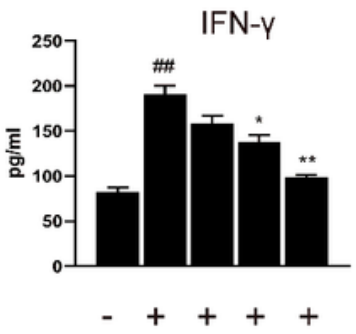

- $\quad 1020$ -

$-\quad-\quad-0.5$

C
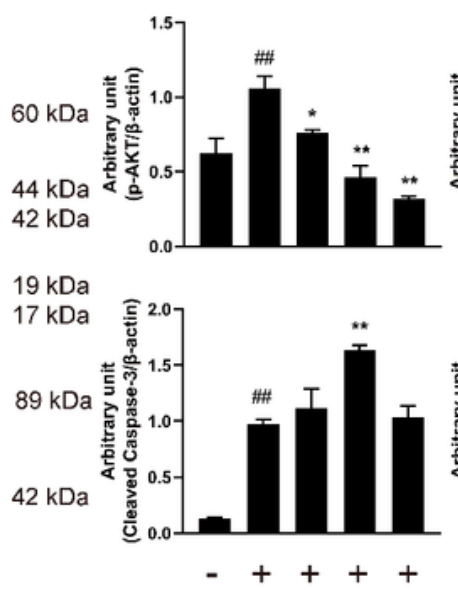

Cleaved
Caspase-3

Cleaved
PARP

$\beta$-actin
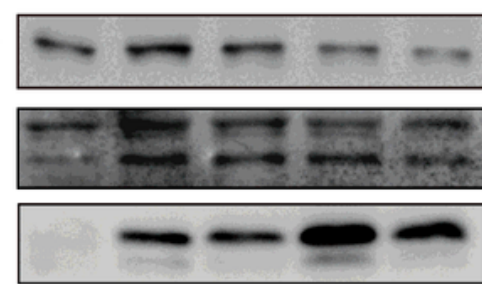

GA
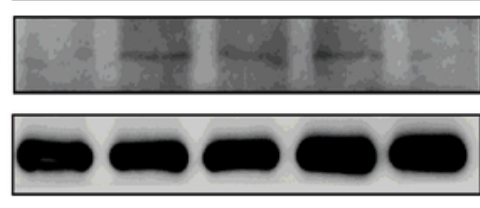

$\operatorname{IsoV}(\mathrm{mg} / \mathrm{kg})$

$\operatorname{Dex}(\mathrm{mg} / \mathrm{kg})$

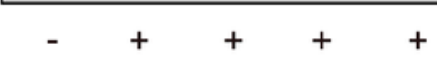

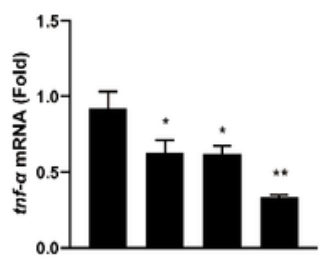
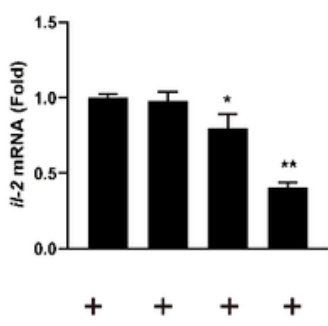

- $1020-$

$-\quad-\quad 0.5$
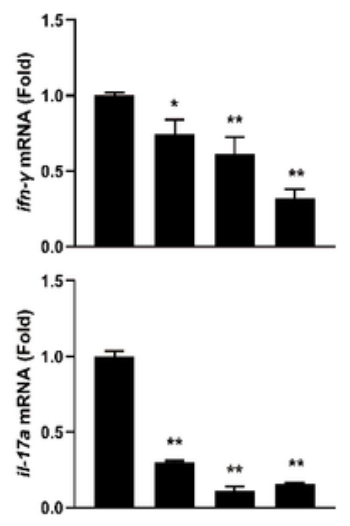

E
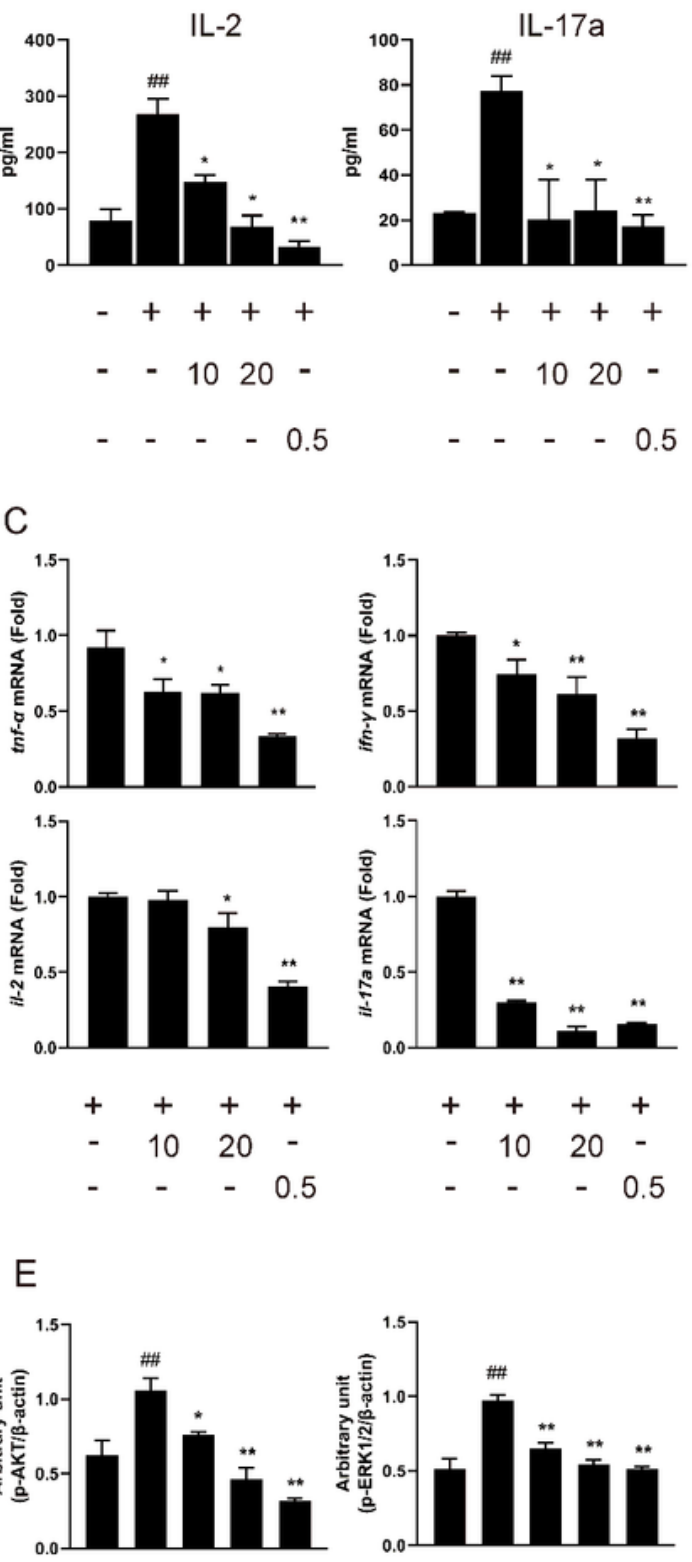

- $-1020-$

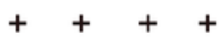

- 1020 -

- $\quad-\quad-0.5$
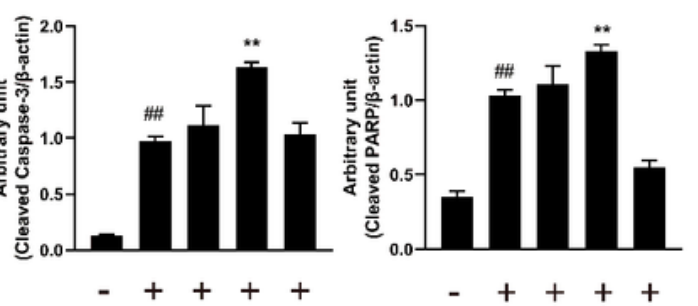

$-++++$

- $\quad 1020$ -

- $\quad 1020-$
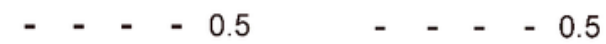

$-\quad-\quad 0.5$

Figure 3

Isovitexin inhibits the expression of pro-inflammatory cytokines in lymph nodes and serum from mice with contact dermatitis and promotes the expression of apoptosis-related proteins. In the mouse model of GA-induced contact dermatitis, (A) the effect of isovitexin on the levels of pro-inflammatory cytokines in 
the serum was determined by ELISA. Data are representative of three independent experiments; $(\mathrm{B}-\mathrm{C})$ the effect of isovitexin on the inflammatory cytokines mRNA expression in lymph nodes was measured by RT-PCR, and the relative band density was analyzed using Image J; (D-E) the lymph node cells were harvested and lysed, and the effect of isovitexin on the protein levels of p-AKT, Cleaved PARP, Cleaved Caspase-3, p-ERK1/2 were analyzed by western blotting, and the relative band density was analyzed using Image $J$. The grouping of gels were cropped from different parts of the different gels. Data represented means $\pm S E M$ of three independent time. \#\#P『0.01 vs vehicle group, ${ }^{*} \otimes 0.05,{ }^{\star} * \mathrm{P} \otimes 0.01$ vs model group. 
A

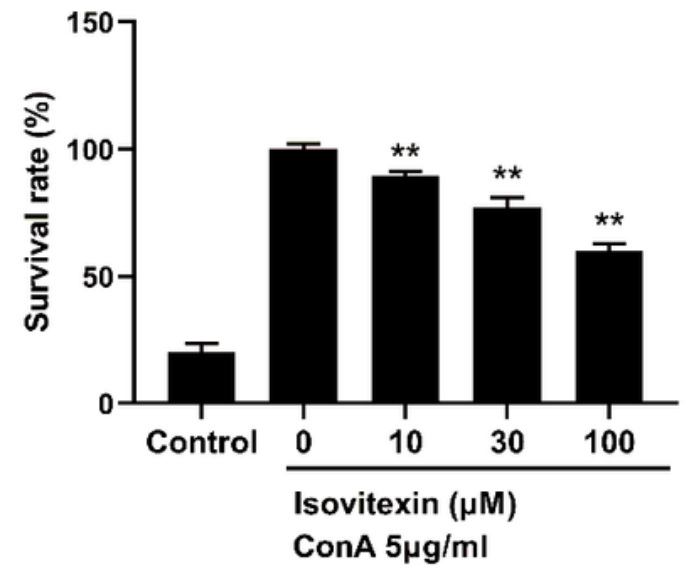

B

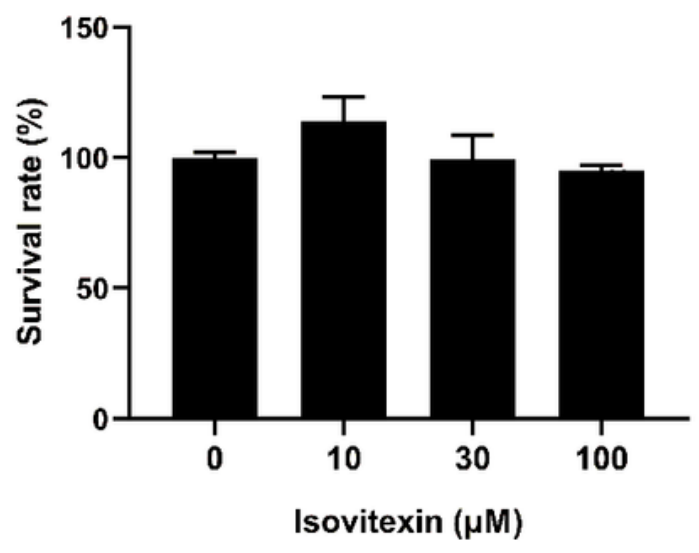

$+$

100
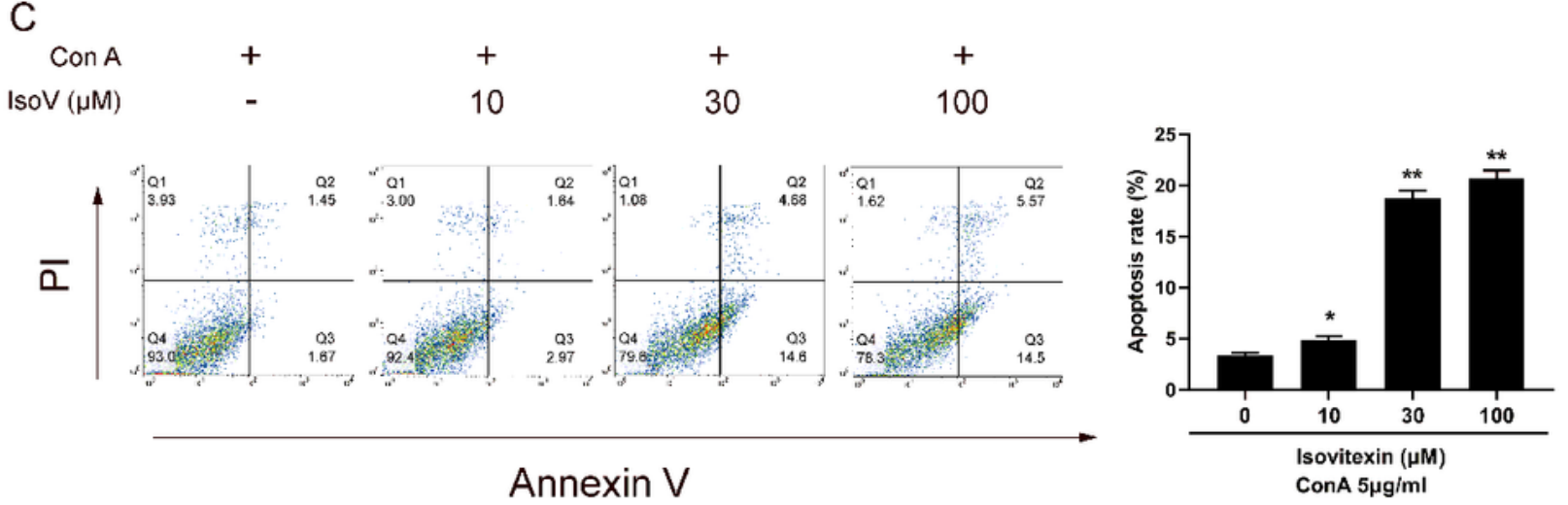

D

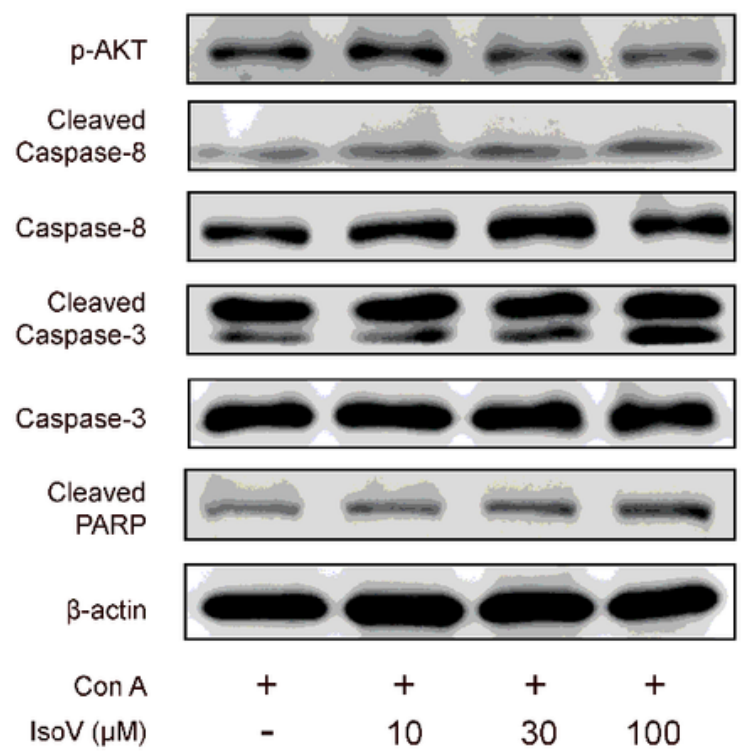

E

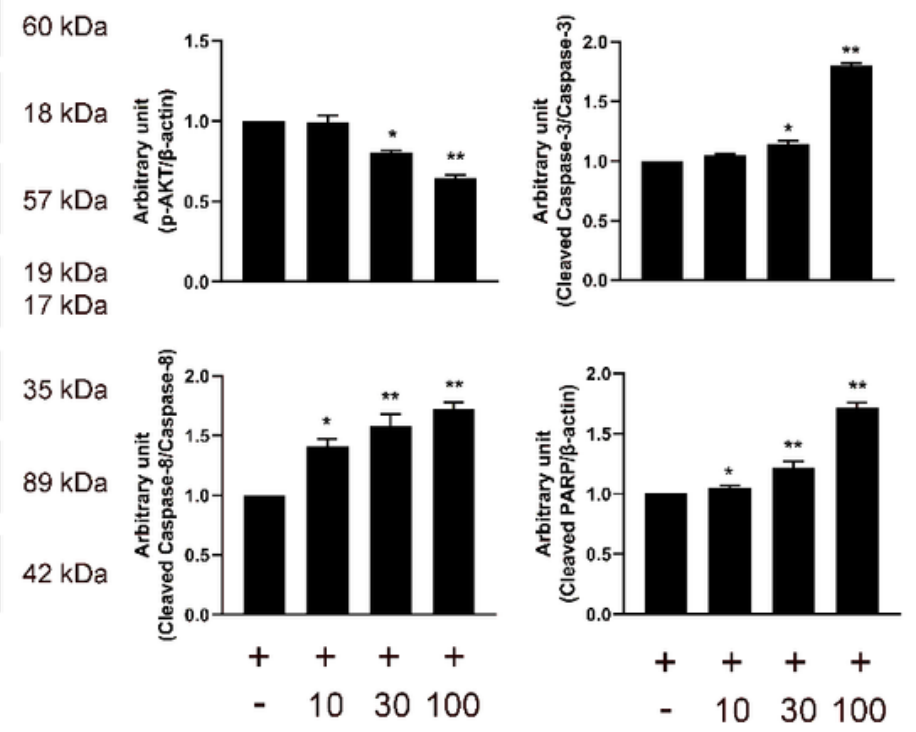

Figure 4

Isovitexin induces the apoptosis of Con A-activated T cells. (A) Con A-activated T cells were treated with different concentrations of isovitexin for 48 hours, and the cell survival was determined by MTT assay. (B) T cells were treated with different concentrations of isovitexin for $24 \mathrm{~h}$, and the cell survival was determined by MTT assay. Cells incubated without Con A and isovitexin were used as control. Con Aactivated T cells were seeded in 12-well plates and incubated with 0, 10, 30 and $100 \mu \mathrm{M}$ isovitexin for 24 
hours. (C) Cells were stained with Annexin $\mathrm{V}$ and $\mathrm{PI}$, and the apoptosis of the cells was determined by flow cytometry assay of Annexin V/PI staining. Annexin $\mathrm{V}$ positive cells of three independent experiments were shown in column statistics. (D-E) Cells treated with different concentrations of isovitexin were harvested and lysed. The protein levels of p-AKT, Cleaved caspase-3, Cleaved caspase-8, Cleaved PARP in T cells were measured by western blotting, and the relative band density was analyzed using Image $\mathrm{J}$. The grouping of gels were cropped from different parts of the different gels. Data represented mean \pm SEM of three independent experiments. \#\#Pख0.01 vs negative control, ${ }^{*} P<0.05,{ }^{\star *} \mathrm{P}<0.01$ vs control (Con A-activated T cells).

A

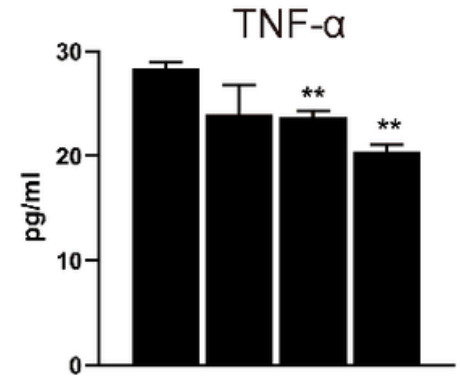

$\operatorname{Con} \mathrm{A}++++$

IsoV $(\mu \mathrm{M}) \quad$ - 1030100

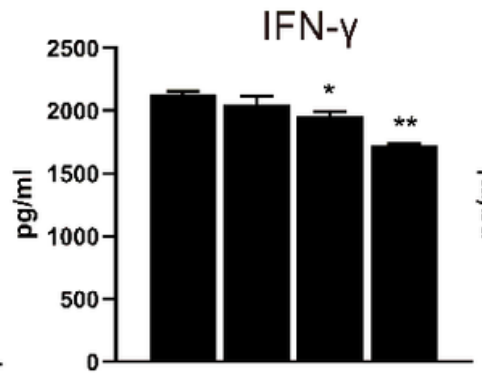

$+\quad+\quad+$

- 1030100

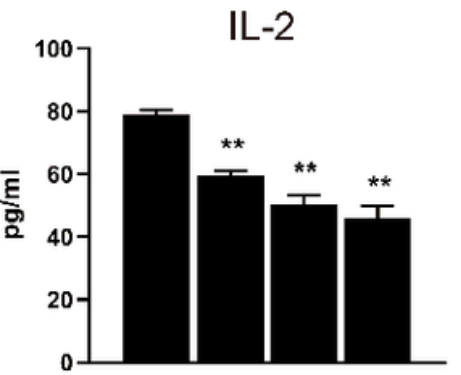

$++++$

- 1030100

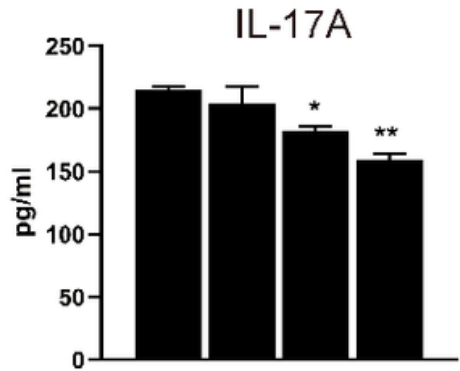

$+\quad+\quad+$

- 1030100
B

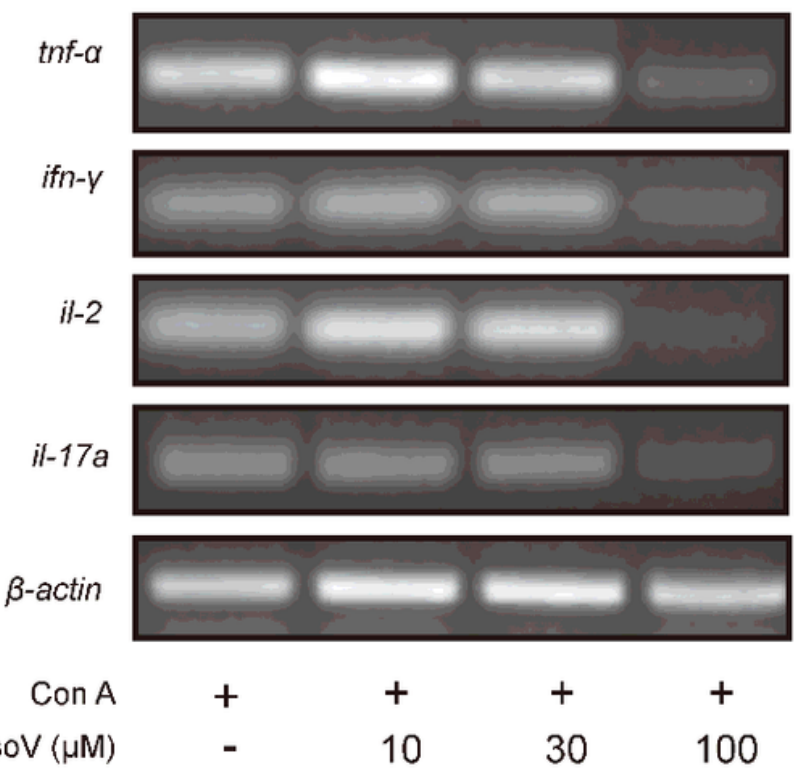

C
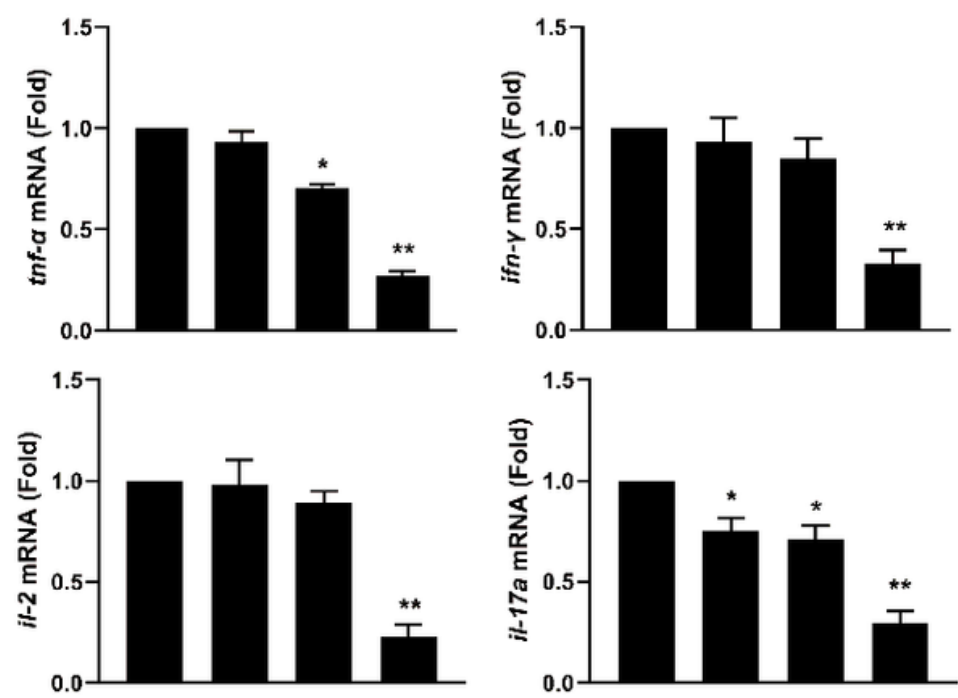

$++++$

- 1030100

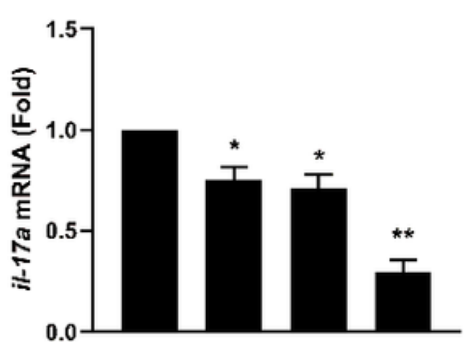

$++++$

- 1030100

\section{Figure 5}

Isovitexin inhibits T cells proinflammatory cytokines production in activated mouse T cells. Con Aactivated T cells were treated with different concentrations of isovitexin for 24 hours; (A)

Proinflammatory cytokines, in culture supernatants of the indicated groups, were determined by ELISA; (B-

C) Relative tnf-a, ifn-y, il-2, il-17a mRNA level was determined by RT-PCR, and relative band density was 
analyzed using Image $\mathrm{J}$. Data are mean \pm SEM and are representative of at least three independent experiments. Significant differences are expressed as $* \mathrm{P}<0.05, * \star \mathrm{P}<0.01$ vs the Con A group.

A
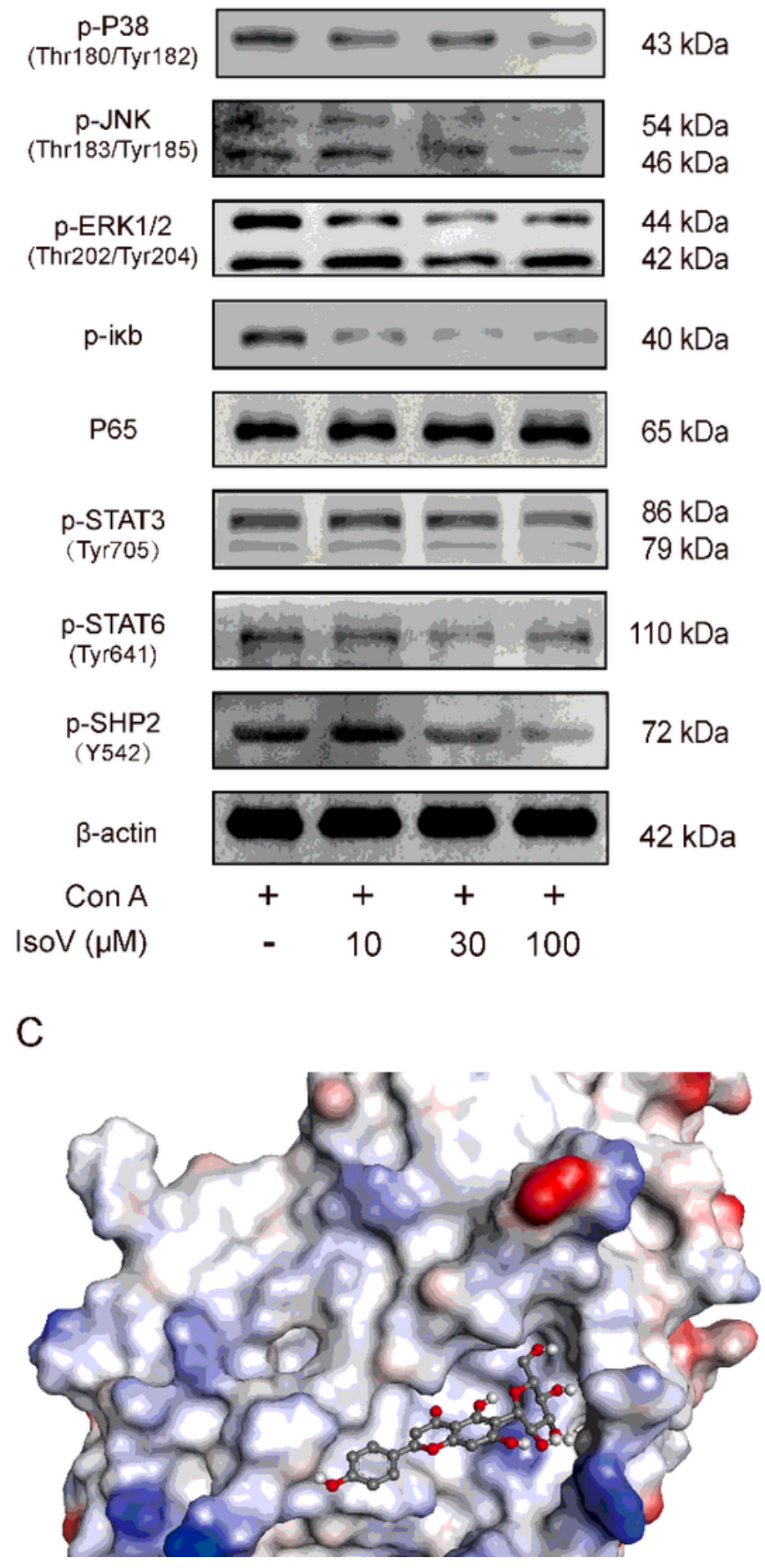

$\mathrm{B}$
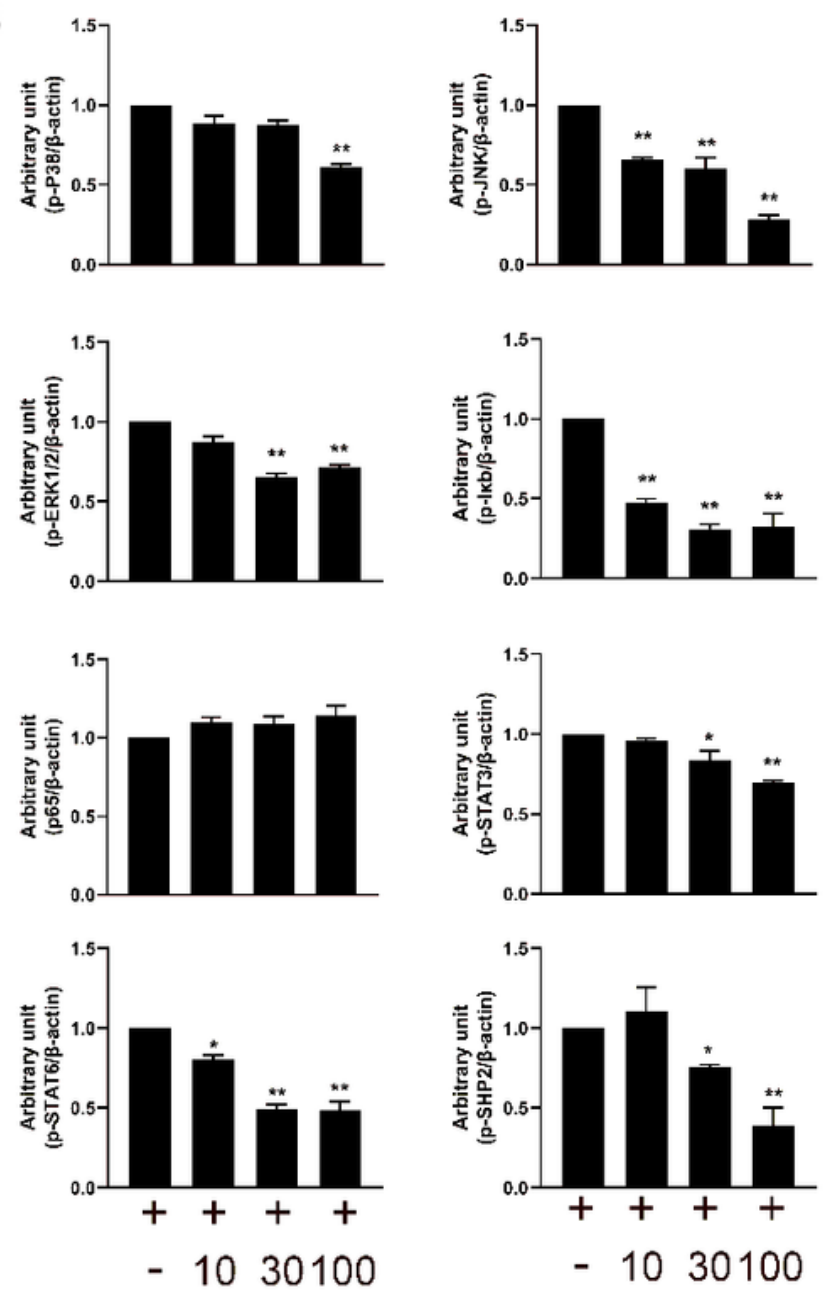

$\mathrm{D}$

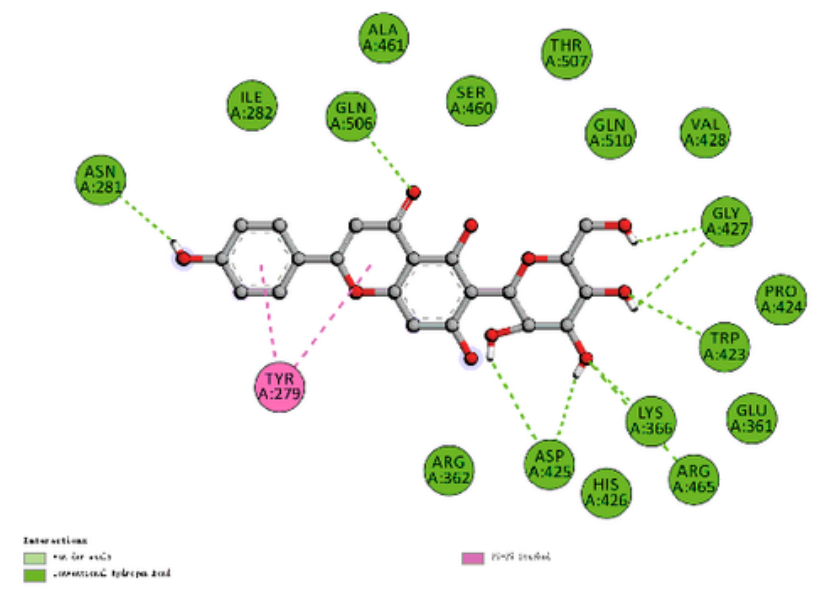

\section{Figure 6}

Isovitexin inhibits MAPK, STAT signaling and decreases the phosphorylated SHP2 level in Con Aactivated T cells. (A-B) T cells isolated from the lymph nodes of Balb/c mice were stimulated with $5 \mu \mathrm{g} / \mathrm{ml}$ Con $A$ and various doses of isovitexin for 24 hours. The protein levels of p-P38, p-JNK, p-ERK1/2, p-ikb, 
P65, p-STAT3, p-STAT6, p-SHP2 in T cells were measured by western blotting, and the relative band density was analyzed using Image $J$ Data are mean \pm SEM and are representative of at least three independent experiments. The grouping of gels were cropped from different parts of the different gels. Significant differences are expressed as ${ }^{*} P<0.05,{ }^{*} \mathrm{P}<0.01$ vs the Con $A$ group. (C-D) The induced fit docking analysis of isovitexin and SHP2 protein (PDB:305x). Hydrogen bonds and $\pi-\pi$ stacking were indicated with green and pink dot line, respectively.

A
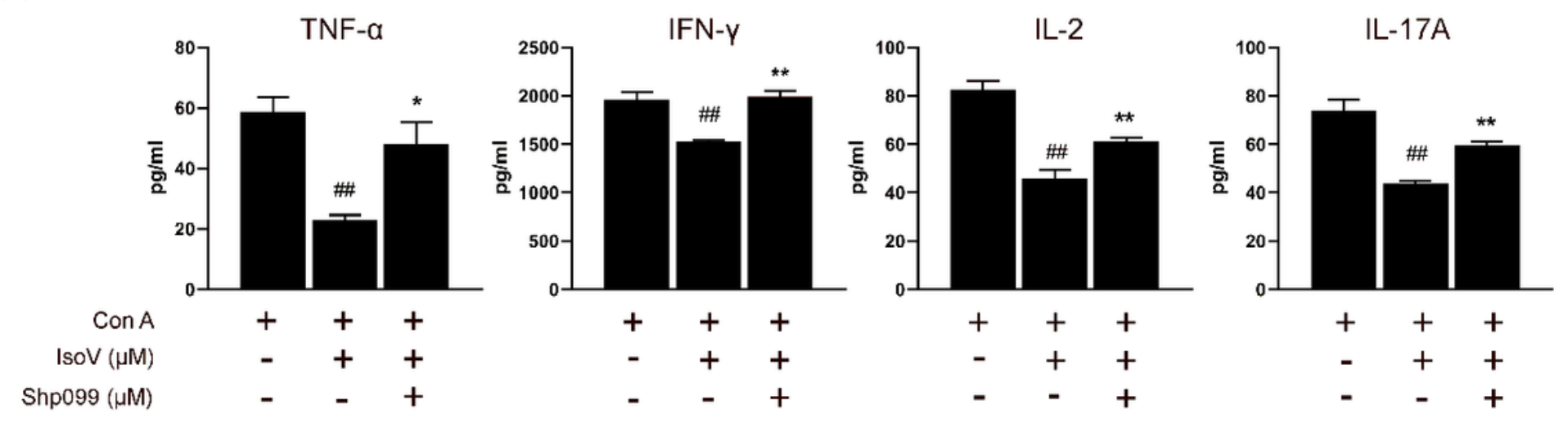

$\mathrm{B}$
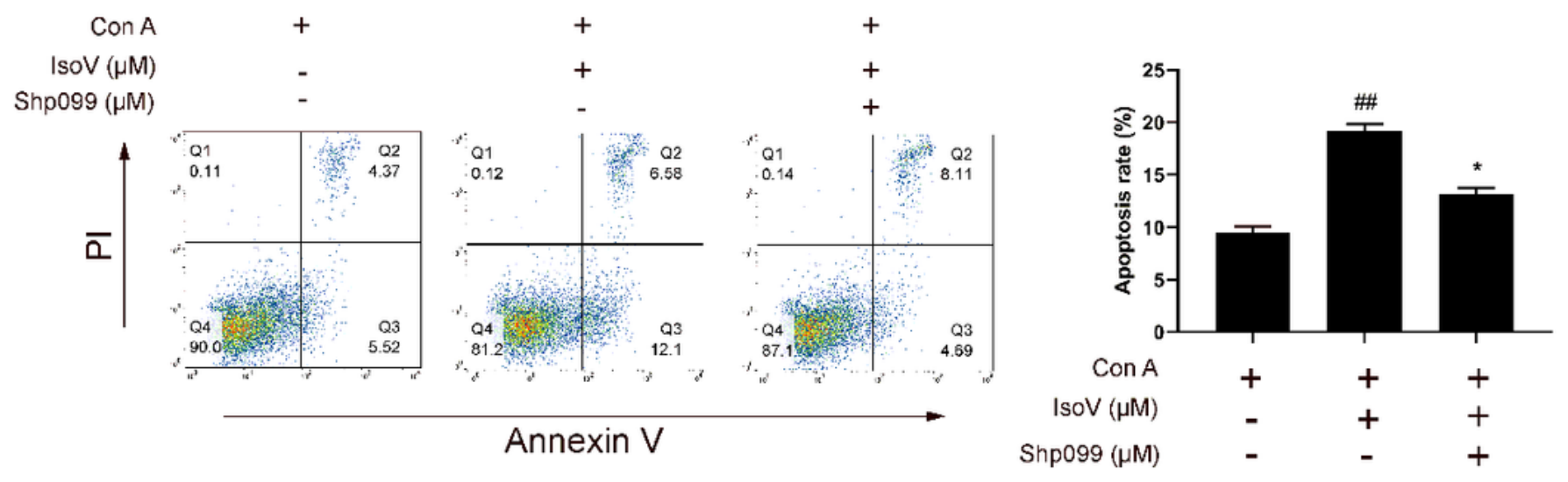

C

D
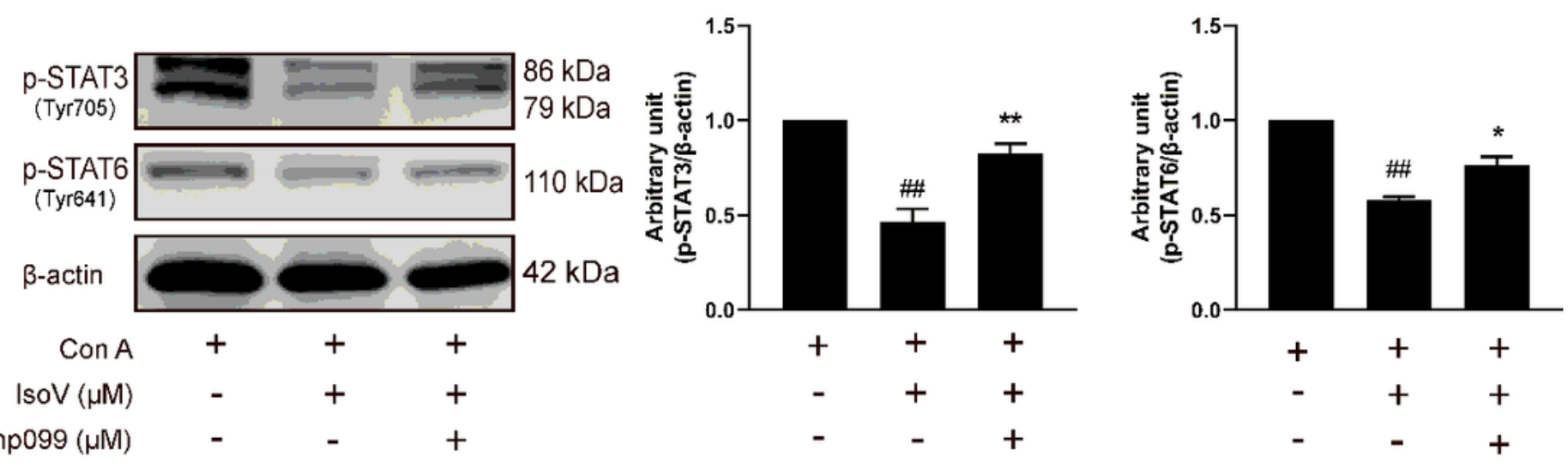

Figure 7 
The SHP2-specific inhibitor SHP099 reversed the effects of isovitexin on activated T cells. Con Aactivated T cells were treated with $100 \mu \mathrm{M}$ isovitexin and added with $10 \mu \mathrm{M}$ SHP2 or not; (A) The levels of proinflammatory cytokines in cell culture supernatants were determined using ELISA kits after 24 hours cultivation. (B) Cells were stained with Annexin V and PI, and the apoptosis of the cells was determined by flow cytometry assay of Annexin V/PI staining. Annexin $\mathrm{V}$ positive cells of three independent experiments were shown in column statistics. (C-D) Lymph nodes cells were harvested and lysed and the phosphorylation of STAT3 and STAT6 was evaluated by Western blot. The grouping of blots was cropped from different parts of the same gel. Data are mean \pm SEM and are representative of two independent experiments. Significant differences are expressed as \#\#P『0.01 vs Con A group, ${ }^{*} P<0.05,{ }^{*} \mathrm{P}<0.01$ vs the isovitexin group. 


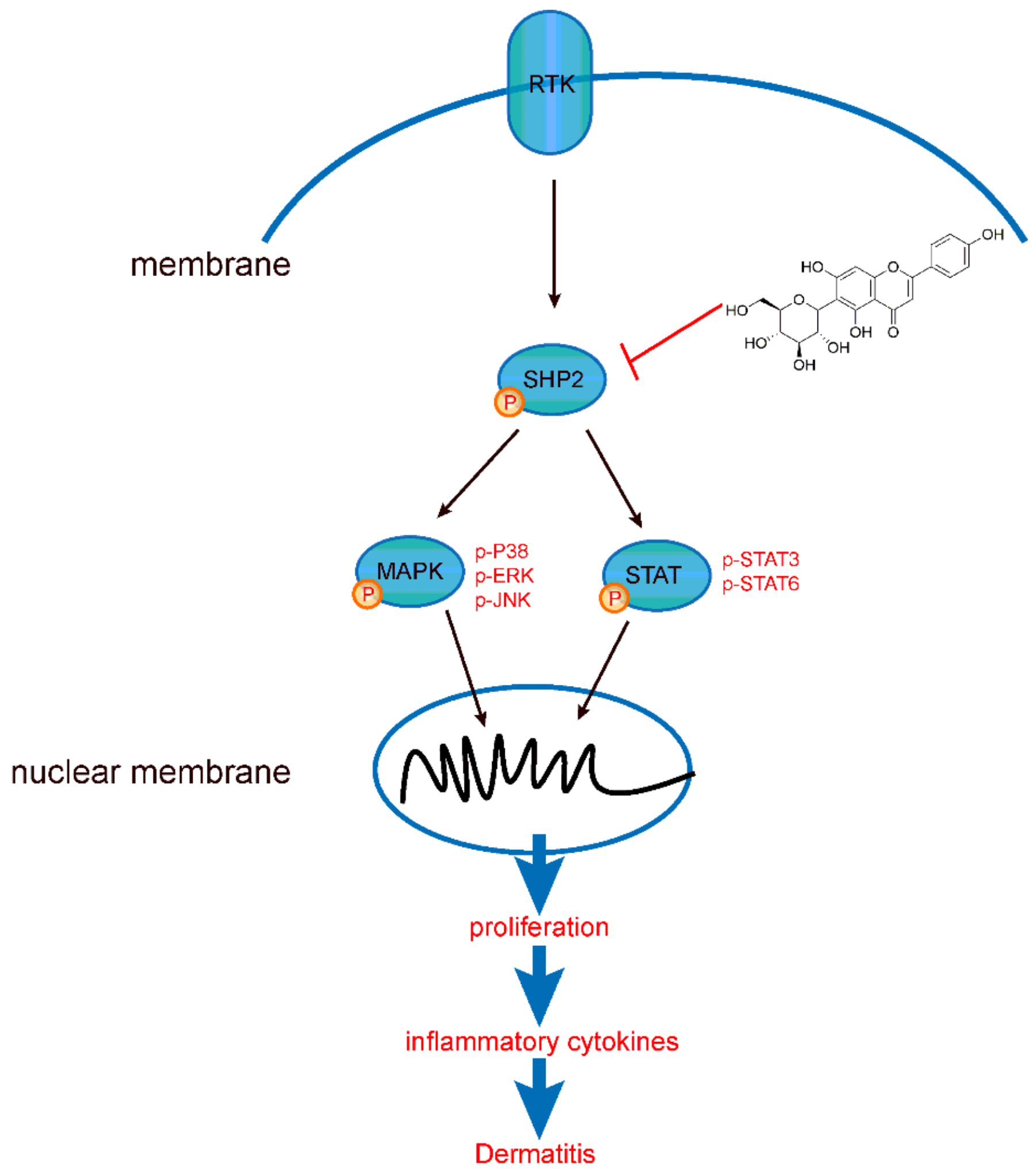

Figure 8

Graphical abstract. When contact hypersensitivity occurs, T cells activated produce proinflammation and chemokine when antigens invade. T cells proliferation and differentiation mediated by receptor tyrosine kinases (RTK) activation, and upregulated its downstream SHP2 protein, MAPK signaling, STAT signaling. On the other hand, isovitexin bind to SHP2 inhibits MAPK signaling, STAT signaling and its dependent 
deactivating programs in T cells, thus decreasing their production of inflammatory cytokines and reducing the severity of dermatitis.

\section{Supplementary Files}

This is a list of supplementary files associated with this preprint. Click to download.

- supplementaryfigure.docx

- supplementaryfigure.docx 